\title{
The Action of Recombinant Human Lysosomal $\alpha$-Glucosidase (rhGAA) on Human Liver Glycogen: Pathway to Complete Degradation
}

\author{
Allen K. Murray ${ }^{1,2}$ (D) \\ 1 HIBM Research Group, Inc., Chatsworth, CA 21053, USA; amurray1@glycantechnologies.com or \\ allen@hibm.org; Tel.: +1-949-689-9664 \\ 2 Glycan Technologies, Inc., P.O. Box 17993, Irvine, CA 92623, USA
}

check for

updates

Citation: Murray, A.K. The Action of Recombinant Human Lysosomal $\alpha$-Glucosidase (rhGAA) on Human Liver Glycogen: Pathway to Complete Degradation. Int. J. Transl. Med. 2021, 1, 381-402. https:// doi.org/10.3390/ijtm1030023

Academic Editors: François Fenaille, Florence Castelli and Benoit Colsch

Received: 29 October 2021

Accepted: 3 December 2021

Published: 14 December 2021

Publisher's Note: MDPI stays neutral with regard to jurisdictional claims in published maps and institutional affiliations.

Copyright: (C) 2021 by the author. Licensee MDPI, Basel, Switzerland. This article is an open access article distributed under the terms and conditions of the Creative Commons Attribution (CC BY) license (https:// creativecommons.org/licenses/by/ $4.0 /)$
Abstract: Glycogen is present in all tissues, but it is primarily stored in the liver and in muscle. As a branched chain carbohydrate, it is broken down by phosphorylase and debrancher enzymes, which are cytoplasmic. It is also degraded by a lysosomal $\alpha$-glucosidase (GAA) also known as acid $\alpha$-glucosidase and lysosomal acid $\alpha$-glucosidase. The deficiency of GAA in patients is known as Pompe disease, and the phenotypes as infantile, juvenile and later onset forms. Pompe disease is treated by enzyme replacement therapy (ERT) with a recombinant form of rhGAA. Following ERT in Pompe mice and human patients there is residual carbohydrate material present in the cytoplasm of cells. The goal of this work is to improve ERT and attempt to identify and treat the residual cytoplasmic carbohydrate. Initial experiments were to determine if rhGAA can completely degrade glycogen. The enzyme cannot completely degrade glycogen. There is a residual glycosylated protein as well as a soluble glycosylated protein, which is a terminal degradation product of glycogen and as such serves as a biomarker for lysosomal glycogen degradation. The glycosylated protein has a very unusual carbohydrate composition for a glycosylated protein: $m$-inositol, $s$-inositol and sorbitol as the major carbohydrates, as well as mannitol, mannose, glucose and galactose. This work describes the residual material which likely contains the same protein as the soluble glycosylated protein. The biomarker is present in serum of control and Pompe patients on ERT, but it is not present in the serum of Pompe mice not on ERT. Pompe mice not on ERT have another glycosylated protein in their serum which may be a biomarker for Pompe disease. This protein has multiple glycosylation sites, each with different carbohydrate components. These glycosylated proteins as well as the complexity of glycogen structure are discussed, as well as future directions to try to improve the outcome of ERT for Pompe patients by being able to monitor the efficacy of ERT in the short term and possibly to adjust the timing and dose of enzyme infusions.

Keywords: rhGAA; Pompe disease; glycogen; lysosomal $\alpha$-glucosidase; acid $\alpha$-glucosidase; lysosomal acid $\alpha$-glucosidase; biomarker; metabolomics

\section{Introduction}

To identify a biomarker by metabolomics sounds simple, and it may be in some cases, but then there are other cases where it may not be so simple. A lot depends on the metabolic pathway involved. In principle, it should just involve the appearance of a breakdown product of the substrate or a conjugated product of the substrate if that is what is involved in the particular pathways. In many cases one may not necessarily be looking for a biomarker but rather investigating the metabolic pathway and something appears which may be a biomarker. With advances in methods of detection of substances, it is becoming clear that well known metabolic pathways may be more complex than what may have long been thought. This is certainly true in the case of glycogen metabolism. In my particular case, I was not looking for a biomarker but rather investigating problems with enzyme replacement therapy (ERT) for a glycogen storage disease, Pompe disease. 
Glycogen, the storage form of glucose in animals, is a complex polymer of glucose consisting of chains of $\alpha-1,4$ linked glucose residues with $\alpha-1,6$ linked branch points about every 12 residues, and it consists of 12 layers with a molecular weight up to $10^{7} \mathrm{kDa}$ [1]. Glycogen is organized into spherical particles of size similar to the calculated size of the spherical model [2,3]. At the reducing end is a protein, glycogenin, which functions as a self-glycosylating primer for the synthesis of the molecule. Glycogen is primarily degraded by phosphorylase for the linear chains and a debranching enzyme to cleave the 1,6 branches. Glycogen and these degradative enzymes are cytoplasmic in all cells but are most abundant in liver and muscle. In addition to the cytoplasmic components of glycogen metabolism, there is a lysosomal $\alpha$-glucosidase which degrades glycogen in lysosomes. About $1-2 \%$ of the cell's glycogen is localized in the lysosomes.

In 1963, H.G. Hers reported the deficiency of the lysosomal $\alpha$-glucosidase (GAA) in Type II glycogenosis which became known as Pompe disease, as well as acid maltase deficiency [4]. His initial report demonstrated the inability to degrade glycogen, but did not specifically report the deficiency of $\alpha-1,6$-glucosidase activity. In 1964, the lysosomal $\alpha$-glucosidase was shown to have $\alpha$-1,6-glucosidase activity in dog liver [5]. In 1970, Brown et al. reported the absence in $\alpha-1,6$-glucosidase in human Pompe disease tissues [6]. The enzyme was shown to be capable of transglucanase, transglucosylation, maltase and glucamylase activities in addition to $\alpha-1,4$-glucosidase and $\alpha-1,6$-glucosidase activities [7-11]. The enzyme is inhibited by maltooligosaccharides above $5 \mathrm{mM}$ concentration [7-11]. The concentration of substrates in vitro or in vivo is unknown since the molecular weight of glycogen is variable and the molecular weight of the soluble fraction is unknown, and concentration only refers to things in solution. The enzyme has been reported to degrade glycogen by $91 \%$, but the inability to completely degrade glycogen when it was $80 \%$ degraded by the lysosomal $\alpha$-glucosidase followed by phosphorylase and debrancher [7]. Another report stated glycogen was $95 \%$ converted to glucose by the rabbit liver lysosomal $\alpha$-glucosidase; however, this was likely a comparison to the glucose released by acid as was a previous report by the same laboratory [10]. It was not possible to detect very small amounts of other carbohydrates at that time. These two studies utilized commercially isolated glycogen which I have found to be partially degraded by chemically harsh procedures $[7,10]$. Many reports give the impression that only glucose is released from glycogen in vivo, but the data reported here indicate that oligosaccharides are released and then converted to glucose in vitro.

There are infantile, juvenile and adult forms of the disease with the infantile involving all tissues but primarily the heart and liver, as well as muscle and the later onset forms primarily involving muscle. The development of the knock-out mouse model for Pompe disease facilitated work which resulted in the development of enzyme replacement therapy [12]. Since 2006, Pompe disease has been treated by enzyme replacement therapy with recombinant GAA (rhGAA). The rhGAA is modified by the addition of mannose-6phosphate residues to take advantage of the Man-6-P receptor to facilitate its entry into tissues and lysosomes [12,13]. The rhGAA is a precursor form of the GAA which is then processed to the mature form by tissues along with the uptake into the cells and lysosomes. Most research over the last 30 years has focused on getting the rhGAA into tissues and the lysosomes.

The complexity of the structure of glycogen and the different activities of the enzyme are often not included in discussions about the deficiency in Pompe disease. As mentioned, GAA has $\alpha-1,4$-glucosidase, $\alpha-1,6$-glucosidase, endoglucanase and glucosyltransferase activities which facilitate its degradation of glycogen [7-11]. This means it can remove a terminal $\alpha-1,4$-linked glucose, a terminal $\alpha-1,6$ linked glucose, it can transfer a glucose to another molecule, or it can cleave internally in a glucose chain and potentially attach it to another molecule. Since in diagrams of pathways, GAA is usually written with an arrow going to glucose, many readers may not be aware of the other activities. For the outer chains of glycogen, the cleavage of one glycosidic linkage may release a glucose residue but for the internal structure more bonds must be cleaved to release a glucose. 
This difference is reflected in the rate of glucose released over time. Some of the results presented here suggest that there may even be another level of organization of glycogen that has not been described.

The present work was begun based on the fact that there are some unresolved issues related to ERT. Following ERT in the Pompe mouse there is residual carbohydrate material, as determined by periodic acid-Schiff (PAS) staining, which accumulates in the cytoplasm [14,15]. This same observation has been made on biopsy tissue from patients following ERT [16,17]. This material has been referred to as glycogen in publications, but it has not been isolated and identified. This may be important since, from my prior work, I know that glycogen contains carbohydrates other than glucose, whereas most investigators are of the belief that glycogen only contains only glucose. It has also been noted that many patients have marked improvement for about 6 months on ERT after which the benefits are not as significant [18]. Both of these observations date back over 15 years. In retrospect, it would seem plausible that initially rhGAA may clear a significant amount of storage material but after some time a portion of the stored material may not be degraded and begins to accumulate $[14,18]$. Therefore, my initial question at the beginning of this work was "Can rhGAA completely degrade Pompe glycogen?" Secondarily, can it completely degrade all glycogen? It is clear that the metabolomics of glycogen degradation by rhGAA is very complex and that we clearly do not understand the complete structure of glycogen.

As stated, GAA has $\alpha-1,4$-glucosidase, $\alpha-1$,6-glucosidase, transglucanase, transglucosylation, maltase and glucamylase activities which coupled with the variabilities in the structure of glycogen means that this is not a straight forward single step enzyme catalyzed reaction from substrate to product [7-10]. The $\alpha-1,6$ glucosidase activity on glycogen cannot be studied kinetically since the actual substrate for the reaction is not known and there may be several possibilities involved. The assumption, conscious or not, has been that glycogen is a homopolymer of glucose. When dealing with a storage disease the term and scope of metabolomics takes on a totally different approach This is because we are no longer trying to determine where the substance goes and intermediates, but our goal is really to determine how every bit of that polymer can be degraded and where it goes. Therefore, this is very different than the traditional way we have learned biochemistry which was primarily related to biosynthesis and not degradation.

\section{Materials and Methods}

\subsection{Source}

Autopsy liver tissue was obtained from an 18-month-old female with Pompe disease (Type II glycogenosis) and from two adult male accident victims. The Pompe liver and the Control 1 liver tissues were obtained at autopsy several hours postmortem. In the case of Control 2, the patient was an organ donor on life support, thus the liver tissue was obtained immediately on termination of life support. All liver tissue was stored at $-76{ }^{\circ} \mathrm{C}$ until the glycogen isolation. The case of the Pompe disease patient and an enzyme replacement trial with lysosomal $\alpha$-glucosidase linked to low-density lipoprotein has been previously reported [19]. Her death was 25 days after a second enzyme infusion.

\subsection{Glycogen Substrates}

The Sigma, Type IX bovine liver glycogen, Sigma-Aldrich, St. Louis, MO, USA, was extracted by the method of Bell and Young, [20] which involves boiling water and TCA precipitation of proteins at elevated temperature. This method is quite harsh compared with the method used in this work for of isolation of the human glycogen.

\subsection{Isolation of Human Glycogen}

The human glycogen was isolated by the method of Mordoh et al. [21] with the addition of five freeze thaw steps to ensure the rupture of lysosomes. This method was chosen because it was reported that the preparation appeared to be identical to native glycogen isolated from liver as judged by its rate of sedimentation and its appearance 
under the electron microscope [21]. Glycogen isolated by this method is reported to be para crystalline [22]. The glycogens were characterized for a number of parameters including average glucose chain length, protein content, amino acid composition, RNA content, phosphate content, $\beta$-amolysis, iodine absorbance, interior chain length and external chain length. The average chain lengths for the control glycogens were 19.9 and for the Pompe glycogen 12.6. The average interior chain lengths were 4.0 and 4.4 for Control 1 and Control 2 , respectively. The average interior chain length for the Pompe glycogen was 3.7. The average exterior chain lengths were 15.9, 15.2 and 8.9 for Control 1, Control 2 and Pompe glycogens, respectively [23-26]. The protein content was less than one per cent for all but one sample. All glycogens were hydrated for at least $18 \mathrm{~h}$ before being used as substrates in assays. Glycogen solutions were never frozen. The tissues were obtained in late 1978 and early 1979 and stored at $-76^{\circ} \mathrm{C}$ until the glycogen was isolated. The isolations were carried out in parallel. The characterization of the glycogen was carried out in 1979. Dr. Metzenberg's master's thesis was submitted in 1980 [23]. The glycogen samples have been stored in a vacuum desiccator over desiccant since that time. I was approached by Genzyme in 2008 as they were aware I had these samples.

\subsection{Enzyme Assays}

Recombinant human GAA was provided by Sanofi Genzyme, Cambridge, MA, USA. This is the $110 \mathrm{kDa}$ precursor which is processed to the mature form by the tissue in ERT. In the case of administration to a patient this precursor was shown by Western blot to result in the $76 \mathrm{kDa}$ active form [27]. The incubation mixtures contained $500 \mu \mathrm{g}$ of glycogen, $50 \mathrm{mM}$ sodium acetate buffer at $\mathrm{pH} 4.6$ and $10 \mu \mathrm{L}$ or $25 \mu \mathrm{L}$ rhGAA $(5 \mu \mathrm{g} / \mu \mathrm{L})$. The mixtures were incubated at $37^{\circ} \mathrm{C}$ under toluene for inhibition of any possible microbial growth At time points indicated in the figures, the reaction mixtures were mixed on a vortex mixer and centrifuged at $16,000 \times g$ for $5 \mathrm{~min}$ to precipitate insoluble material. Aliquots of $100 \mu \mathrm{L}$ or $200 \mu \mathrm{L}$ were extracted and boiled for $5 \mathrm{~min}$ in screw cap vials. Samples were again centrifuged at $16,000 \times g$ for $5 \mathrm{~min}$ to precipitate and insoluble material and the supernatants were analyzed by HPAEC-PAD using a PA- 1 column. The incubation mixture was mixed on a vortex mixer before being replaced in the water bath.

\subsection{Carbohydrate Analysis}

HPAEC-PAD was performed on a Dionex DX-600 ion chromatograph, Thermo Fisher Scientific, Waltham, MA, USA, using a Dionex CarboPac PA-1 column. The eluent was $150 \mathrm{mM}$ sodium hydroxide, isocratic from 0 to $5 \mathrm{~min}$ then a linear sodium acetate gradient from 5 to $25 \mathrm{~min}$ from 0 to $57 \% 500 \mathrm{mM} \mathrm{NaOAc}$ in $150 \mathrm{mM} \mathrm{NaOH}$ at a flow rate of $1 \mathrm{~mL} / \mathrm{min}$. Fractions were collected using a Gilson 202 fraction collector, Gilson Scientific, Middleton, WI, USA, dialyzed overnight against 18.3 megohm water in $1.0 \mathrm{~mL}$ chambers with a 500 MWCO membrane. Fractions were combined and taken to dryness in a SpeedVac. Fractions were then hydrolyzed with 2 N TFA at $100{ }^{\circ} \mathrm{C}$ for two hours after which they were taken to dryness in a Speed-Vac. If it was determined that hydrolysis was incomplete, samples were hydrolyzed with $4 \mathrm{~N}$ TFA at $120{ }^{\circ} \mathrm{C}$ for 1 to $4 \mathrm{~h}$. Monosaccharides and sugar alcohols were determined using a Dionex CarboPac MA-1 column with isocratic elution with $612 \mathrm{mM}$ or $480 \mathrm{mM} \mathrm{NaOH}$ at a flow rate of $0.4 \mathrm{~mL} / \mathrm{min}$. The waveform for carbohydrate analysis had a potential of $+0.1 \mathrm{~V}$ from 0 to $0.40 \mathrm{~s},-2.0 \mathrm{~V}$ from 0.41 to $0.42 \mathrm{~s}$, $+0.6 \mathrm{~V}$ from 0.43 to $0.44 \mathrm{~s}$ and $-0.1 \mathrm{~V}$ from 0.44 to $0.50 \mathrm{~s}$ with integration from 0.20 to $0.40 \mathrm{~s}$. Data analysis was performed using Dionex Chromeleon software, Thermo Fisher Scientific, Waltham, MA.

\subsection{Amyloglucosidase Assay}

Assay mixtures consisted of $1 \mathrm{~mL}$ volume containing $500 \mu \mathrm{g}$ of glycogen, $50 \mathrm{mM}$ sodium acetate buffer, $\mathrm{pH} 4.6$ and $100 \mu \mathrm{L}$ amyloglucosidase, $1 \mathrm{mg} / \mathrm{mL}, A$. niger, Sigma A-7420. The reactions were incubated at $55^{\circ} \mathrm{C}$. Incubations were for 2 or $5 \mathrm{~h}$ and boiled for $5 \mathrm{~min}$ to stop the reaction, after which they were centrifuged for $5 \mathrm{~min}$ at $16,000 \times g$. 


\subsection{Maltooligosaccharides and Amyloglucosidase}

Maltooligosaccharides and amyloglucosidase were purchased from Sigma Aldrich Chemical Company. Maltooligosaccharides and their determined glucose content were as follows: maltotriose, $67.2 \%$; maltotetraose, $89.1 \%$; maltopentaose, $97.7 \%$; maltohexaose, $94.4 \%$; maltoheptaose, $84.7 \%$.

\subsection{Acid Hydrolysis of Glycogen Residues}

The insoluble precipitate, which appeared to be stuck to the bottom of the tube, was washed three times with water by agitation on a vortex mixer and centrifugation. Following the washing the material was hydrolyzed in 2 N TFA for $3 \mathrm{~h}$ at $100{ }^{\circ} \mathrm{C}$, dried in a Speed-Vac, Savant, Thermo Fisher Scientific, Waltham, MA, USA, and taken up in water for chromatography.

\subsection{Protein Determination}

Protein determination on the TFA hydrolyzates was by a modification of the method of Lowry et al. [28]. A control experiment of protein determination on bovine serum albumin (BSA) showed no significant difference between samples of before and after hydrolysis for comparison.

\subsection{0. $\mathrm{KOH}$ Treatment of Glycogen}

Control 2 glycogen, $30.8 \mathrm{mg}$, in $30 \% \mathrm{KOH}$ was boiled for $60 \mathrm{~min}$. It was precipitated in $90 \% \mathrm{EtOH}$, washed, re-precipitated and taken to dryness. The final weight was $30.2 \mathrm{mg}$. The starting glycogen was opaque in the solution. The final material was clear in a solution of $10 \mathrm{mg} / \mathrm{mL}$ indicative of a significant change. Reports in the literature indicate that this $\mathrm{KOH}$ treatment generally reduces the glycogen to about half of its original molecular weight. The protein content of Control 2 glycogen was $1.7 \%$, and the protein content of the Control 2 glycogen, $\mathrm{KOH}$-treated, was $0.16 \%$.

\section{Results}

Metabolomics issues will be discussed first, then biomarkers later.

\subsection{Enzymatic Hydrolysis of Glycogen}

Glucose released from the Pompe liver glycogen and the control glycogens is shown in Figure 1. A comparison of the glycogen samples revealed that more glucose was released from the Pompe glycogen in the initial $24 \mathrm{~h}$ than from the two control glycogens when $10 \mu \mathrm{L}(5 \mu \mathrm{g} / \mu \mathrm{L})$ of rhGAA was used in the $1 \mathrm{ml}$ reaction mixture containing $0.5 \mathrm{mg}$ of glycogen. There was a noticeable lag period after which the glucose released from the controls approached the others. This lag period was not observed when the incubation was started with $25 \mu \mathrm{L}$ of rhGAA $(5 \mu \mathrm{g} / \mu \mathrm{L})$ in the $1 \mathrm{ml}$ reaction mixture. It is interesting to note that each glycogen sample appears to be somewhat different by the rate of degradation and the time frame in which the intermediates appear.

A similar result was obtained for all glycogens analyzed although only one Pompe liver glycogen is shown. The centrifuging before sampling was carried out to prevent insoluble glycogen from being removed from the incubation tube. The replacement of buffer containing rhGAA at $120 \mathrm{~h}$ was carried out to replace volume lost due to sampling and to reduce the free glucose concentration which might inhibit the enzyme. The reactions were allowed to proceed until no more glucose was released. At that point, there was a visible residue which was stuck to the bottom of the tube. 


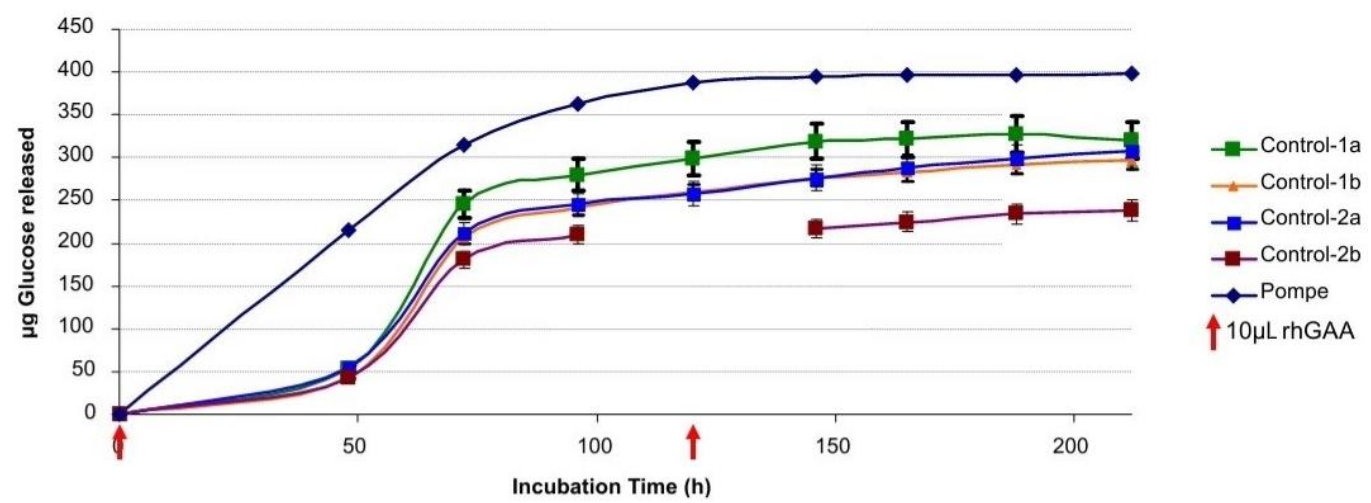

Figure 1. Glucose released from glycogens. Red arrows indicate time of addition of rhGAA. Data points are the average of 3 determinations except for Pompe to conserve sample. The Control 1a and Contol $2 \mathrm{a}$ were from the respective glycogens hydrated on one date and the Control $1 \mathrm{~b}$ and Control $2 \mathrm{~b}$ were from glycogens hydrated on a different date. There is no $120 \mathrm{~h}$ time point for Control $2 \mathrm{~b}$ due to 2 screw cap aliquot tubes leaking during the boiling.

The significance of these results of the glucose released is that whereas rhGAA incubation resulted in the release of increasing amounts of glucose with time, it did not release the minor constituents [24]. In a time course of TFA hydrolysis, the minor constituents are not released until well after the glucans are hydrolyzed [25]. This was taken to indicate that the monosaccharides other than glucose are not intercalated with the glucose in glycogen. However, since they are present in the hydrolyzate of the residual material after no more glucose is released, it appears that that glycogen is not homogeneous and that the glucose in the $\alpha$-glucosidase resistant component cannot be accessed by the $\alpha$-glucosidase. However, the enzyme is able to access almost all of the glucose. The monosaccharide composition of the $\alpha$-glucosidase resistant material contains hexoses and alditols which are not released by the $\alpha$-glucosidase action on glycogen as shown in Figure 5. This is also indicative of the heterogeneity of glycogen. Figure 2 shows glucose released from Control 2 glycogen and the calculated daily remaining glycogen substrate, glucose released per day and the content of rhGAA remaining.

Glucose Released from Control 2 Glycogen

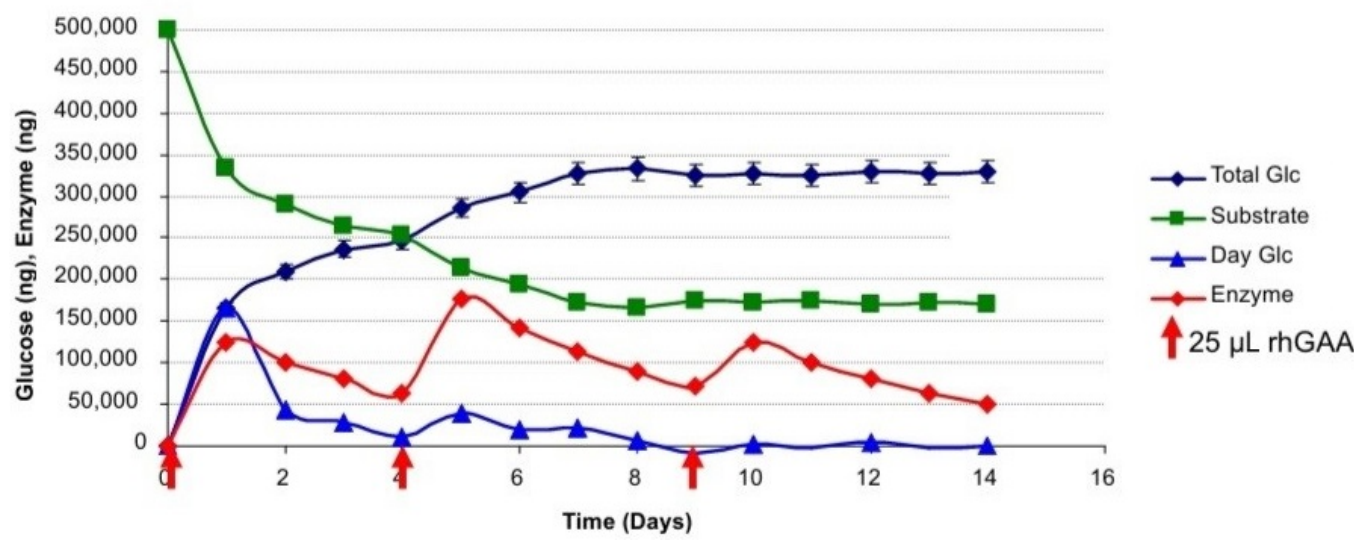

Figure 2. Glucose released from Control 2 glycogen and the calculated remaining glycogen substrate, daily glucose released and the rhGAA remaining. Glucose determinations are an average of 8 tubes for the total glucose released (dark blue line). The other values are calculated from the glucose released and the volume remaining in the incubation tubes for the enzyme content. 
It may be that only glucose is released in vivo, but from work with glycogen as a substrate, it appears that oligosaccharides are also released in vitro and are then degraded to glucose likely within the lysosome. The oligosaccharides released into the medium during glycogen degradation by rhGAA typically are maltose, isomaltose, maltotriose and maltotetraose. Isomaltose is an $\alpha-1,6$-linked glucan, whereas the others are $\alpha-1,4$-linked glucans of 2,3 or 4 glucose residues, respectively.

However, if the samples are incubated with rhGAA for $24 \mathrm{~h}$ and the incubation medium is replaced with $50 \mathrm{mM}$ Tris- $\mathrm{HCl}, \mathrm{pH} 6.7$ for an additional $24 \mathrm{~h}$ a number of intermediates are released into the Tris- $\mathrm{HCl}$ solution as shown in the chromatograms in Figure 3A-D. The the bar plot of glucose released after the first $24 \mathrm{~h}$ of degradation by rhGAA is shown in Figure 3E. This shows that the rate of glucose released is reduced if the glycogen has a highly complex structure although oligosaccharides are released. The Sigma glycogen was completely degraded in the $24 \mathrm{~h}$ period. As mentioned, the Sigma glycogen is produced by an isolation procedure which is very harsh and as a result was completely degraded in $24 \mathrm{~h}$. The human glycogens were isolated by a gentle procedure chosen for the reason that the glycogen was found to closely resemble glycogen in tissue [22]. Another factor is the time period between death and freezing of the tissue. Control 1 and Pompe liver tissue was obtained at autopsy; however, Control 2 liver tissue was taken from an organ donor; it was diced and placed on ice immediately on removal and frozen on dry ice within minutes. The time period between death and when the tissue was frozen appears to have a significant effect on the degree of complexity of the glycogen subsequently isolated from the tissue. This rapid degradation of glycogen after death has been reported to occur within minutes for animal tissues [29].

When the Tris- $\mathrm{HCl}$ buffer was washed out and the original incubation medium containing the rhGAA was replaced and the tubes returned to the water bath, no more glucose was released for $48 \mathrm{~h}$. At that point the release of glucose resumed, and the rate of glucose release resembled that of incubations not interrupted by the Tris- $\mathrm{HCl}$ treatment. Obviously, oligosaccharides and higher structures were being degraded to a point where glucose was then released. In the case of the use of phosphate buffer to raise the $\mathrm{pH}$ no oligosaccharides were detected in the extract after $24 \mathrm{~h}$. In addition, after removal of the phosphate buffer and replacement of the initial medium with rhGAA, no more glucose was released over several days. To determine if the rhGAA was still active, additional glycogen was added and it was degraded as usual with the release of glucose. If glycogen was incubated in the phosphate buffer for $24 \mathrm{~h}$ and the phosphate washed out before the incubation media with rhGAA added, the glycogen was degraded as usual. Therefore, if glycogen is incubated with rhGAA and then switched to phosphate buffer, the glycogen cannot be further degraded by switching back to the media with rhGAA. This is a very interesting observation, but I do not have an explanation for what is happening. This bears further investigation.

The differences in the rates of degradation of the different glycogens demonstrates that the rate of degradation of glycogen by rhGAA can only be compared by using glycogen from the same isolation batch. This means that the rate of glycogen degradation between any two experiments cannot be used as an indicator of enzyme activity unless both experiments were carried out using the same batch of glycogen.

The variable rates of degradation of different glycogen samples raises several questions: Does the glycogen from one individual vary the glycogen of another individual? Does the glycogen in an individual vary in structure, in addition to quantity, from time to time based on the metabolic state and perhaps other unknown factors? No two batches of isolated glycogen can be considered equivalent. 

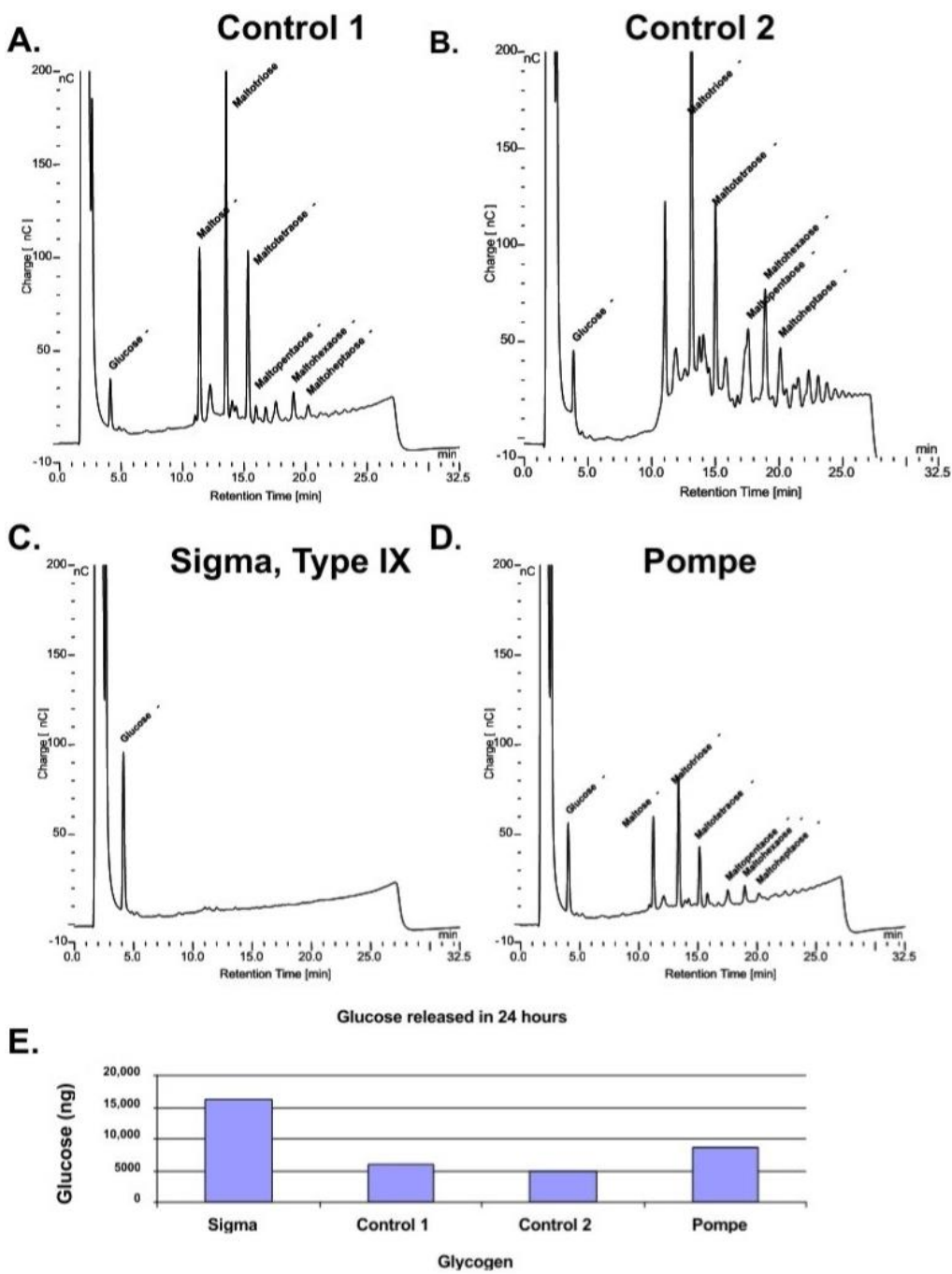

Figure 3. Carbohydrates in the supernatant released by Tris- $\mathrm{HCl}$ buffer after $24 \mathrm{~h}$ rhGAA incubation. (A) Control 1 glycogen, (B) Control glycogen, (C) Sigma, Type IX glycogen, (D) Pompe glycogen, (E) Glucose released from glycogens. Glycogen (500 mg, $25 \mathrm{~mL}, 500 \mathrm{mM} \mathrm{NaOAc}, \mathrm{pH} 4.6$ in $1.0 \mathrm{~mL}$ ) was incubated at $37^{\circ} \mathrm{C}$ for $24 \mathrm{~h}$. Tubes were centrifuged at $16,000 \times \mathrm{g}$ for $5 \mathrm{~min}$ and rhGAA incubation. The medium was replaced with $50 \mathrm{mM}$ Tris- $\mathrm{HCl}, \mathrm{pH} 8.0$ and incubated for $24 \mathrm{~h}$ at $37^{\circ} \mathrm{C}$. The Tris- $\mathrm{HCl}$ medium was the analyzed by HPAEC-PAD. The later eluting peaks are quantitatively the major components. This is not apparent because different carbohydrates have different detector responses; therefore, it is not possible to compare peaks in the same chromatogram to each other to determine quantitative relationships. Each peak must be compared with a standard curve.

\subsection{Specific Activity and Apparent Specific Activity}

The apparent specific activity of the rhGAA on glycogen is lower than the specific activity on artificial or low molecular weight substrates such as 4-methylumbelliferyl $\alpha$-D-glucose or maltose. The problem with the 4-methylumbelliferyl or $p$-nitrophenyl- $\alpha$-Dglucose substrates is that they are a very low molecular weight substrates compared with glycogen and not what the enzyme acts on in tissue. For this reason, specific activity for rhGAA was determined using maltose and the apparent specific activity against glycogen as substrates; therefore, the specific activity of the enzyme against them is much higher than against any natural substrate. The specific activity of $42.8 \mathrm{U} / \mathrm{mg}$ at $\mathrm{pH} 4.6$ compares favorably with the specific activity of $32.7 \mathrm{U} / \mathrm{mg}$ at $\mathrm{pH} 4.5$ and $10 \mathrm{mM}$ maltose for the lysosomal $\alpha$-glucosidase [30]. It should also be kept in mind that a glycosyl hydrolase is a special case of a transferase which uses water as the acceptor alcohol. 
Apparent Specific Activity: Glycogen Substrates

The true specific activity of GAA cannot be determined against glycogen due to a lack of knowledge of the glycogen structure that is the substrate the enzyme acts on [8]. Experiments have demonstrated a difference in rhGAA activity with different glycogen substrates as shown in Figure 3. For this reason, both Sigma Type IX glycogen and Control 2 human glycogen were used at two different content levels in the reaction. It is not proper to refer to glycogen as a concentration since concentration refers to substances in solution and all of the glycogen is not in solution, thus content in the reaction mixture is used. To determine if configuration of the glycogen makes a difference in the apparent specific activity, in addition to native glycogen, glycogen was also boiled for $5 \mathrm{~min}$ before the assay and $0.1 \mathrm{~N} \mathrm{HCl}$ extracts were also used. The free glucose in the $\mathrm{HCl}$ extracts was subtracted from that released by the enzyme.

The apparent specific activities against the native, boiled and $0.1 \mathrm{~N} \mathrm{HCl}$ extracts of Sigma, Control 1, Control 2, Pompe and KOH-treated Control 2 glycogens are shown in Table 1 . These are the results from $24 \mathrm{~h}$ incubations at a wide range of substrate contents from 400 to $8000 \mathrm{mg} / \mathrm{mL}$. In all cases, the human glycogens have the lowest apparent specific activity for the native glycogen, higher for the boiled glycogen and much higher for the $\mathrm{HCl}$ extract. The Sigma glycogen has very similar values for the native and boiled glycogen and somewhat higher for the $\mathrm{HCl}$ extract. The $\mathrm{KOH}$ Control 2-treated glycogen has values significantly higher than the native Control 2 glycogen and with less difference between them similar to the Sigma glycogen. These data demonstrate the difference between glycogens and the fact that the Sigma glycogen is significantly degraded which is consistent with the data in Figure 3. These data again show that apparent specific activity of the enzyme is dependent on the glycogen substrate and that they are all different. Chromatograms of typical initial starting incubations for the native, boiled and $\mathrm{HCl}$ extracts are shown in Figure 4. There is only some free glucose in the $\mathrm{HCl}$ extract; therefore, it was subtracted from the glucose liberated.

Table 1. Apparent specific activity of rhGAA on different glycogens. Activity is expressed on the basis of glucose released during the first $24 \mathrm{~h}$ of multi-day incubations on a per hour basis. Substrate content in the incubation mixtures range from 400 to $8000 \mathrm{mg} / \mathrm{mL}$. Activity is express as $\mu$ mole glucose released $/ \mathrm{h}$. Glycogen indicates native, $\mathrm{b}$ indicates boiled $5 \mathrm{~min}$ and $\mathrm{h}$ indicates the $\mathrm{HCl}$ extract.

\begin{tabular}{cccccc}
\hline Glycogen & $\mu \mathrm{g} / \mathbf{m L}$ & $\mu \mathbf{m o l} / \mathbf{m g} / \mathbf{h}$ & Glycogen & $\mu \mathbf{g} / \mathbf{m L}$ & $\mu \mathbf{m o l} / \mathbf{m g} / \mathbf{h}$ \\
\hline Control 1 & 400 & 0.20 & Pompe & 800 & 0.41 \\
Control 1b & 400 & 0.75 & Pompe b & 800 & 0.73 \\
Control 1h & 400 & 1.93 & Pompe h & 800 & 1.93 \\
Control 1 & 800 & 0.21 & Sigma & 4000 & 7.52 \\
Control 1b & 800 & 1.05 & Sigma b & 4000 & 7.70 \\
Control 2h & 800 & 3.20 & Sigma h & 4000 & 7.80 \\
Control 2 & 4000 & 0.68 & Sigma & 8000 & 10.54 \\
Control 2b & 4000 & 2.07 & Sigma b & 8000 & 10.18 \\
Control 2h & 4000 & 7.15 & Sigma h & 8000 & 9.77 \\
Control 2 & 8000 & 1.17 & Cont2KOH & 1000 & 2.21 \\
Control 2b & 8000 & 3.18 & Cont2KOHb & 1000 & 2.72 \\
Control 2h & 8000 & 8.44 & Cont2KOHh & 1000 & 3.91 \\
Pompe & 400 & 0.31 & Cont2KOH & 2000 & 3.73 \\
Pompe b & 400 & 0.56 & Cont2KOHb & 2000 & 4.60 \\
Pompe h & 400 & 1.42 & Cont2KOHh & 2000 & 6.38 \\
\hline
\end{tabular}




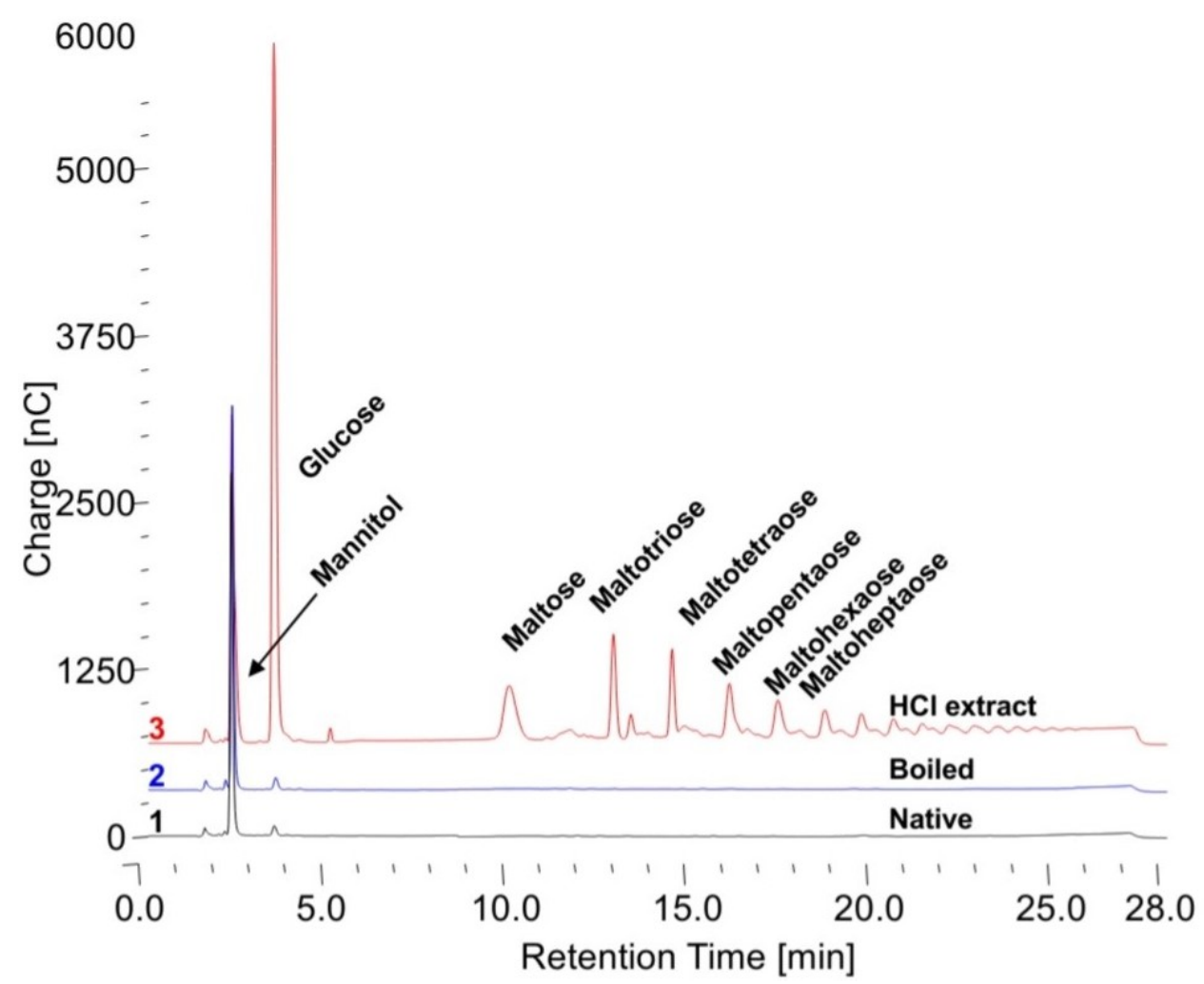

Figure 4. Native, boiled and $\mathrm{HCl}$ extracted Control 2 glycogen at the beginning of incubations with rh GAA. The peak at $10 \mathrm{~min}$ is maltose and the peak at just over $5 \mathrm{~min}$ is isomaltose. The source of mannitol is the rhGAA which is packaged in mannitol.

\subsection{Residue from Enzymatic Degradation of Glycogen}

The carbohydrate composition of the residues from rhGAA degradation of glycogen is shown in Figure 5 and the total carbohydrate and protein composition is shown in Table 2. The difference in glucose content of Control 1 and Control 2 glycogen residues and the residues from Pompe glycogen and $\mathrm{KOH}$-treated Control 2 glycogen is striking. The $\mathrm{KOH}$ treatment changes the structure enough that the rhGAA can access much more of the glucose which is consistent with the relative specific activity against the $\mathrm{KOH}$-treated Control 2 indicated in Table 1 . The $\mathrm{KOH}$-treated Control 2 glycogen has a less complex structure as a result of the $\mathrm{KOH}$ treatment. This difference is consistent with the results shown in Figures 1 and 3 for the Control and Pompe glycogens. Clearly, rhGAA has greater access to the glucose containing structures in Pompe and $\mathrm{KOH}$-treated Control 2 glycogens. The residue material is not a purified fraction but rather a mixture of the residues from all of the oligosaccharides of a glycogen which are shown in Figure 5 and discussed further in Murray et al. [24]. At this time, the nature of the association of the protein and carbohydrate components with the oligosaccharide components of glycogen is not known. However, if the chromatography of oligosaccharides, such as maltotriose, does not employ an acetate gradient the small peaks are not resolved [24].

Table 2. Carbohydrate and protein components of glycogen residue components as $\mu \mathrm{g} / \mathrm{mg}$ glycogen.

\begin{tabular}{cccc}
\hline Glycogen & Carbohydrate & Protein & Total \\
\hline Sigma & 7.7 & 23.2 & 39.0 \\
Control 1 & 21.4 & 48.0 & 69.5 \\
Control 2 & 7.3 & 30.0 & 37.3 \\
Pompe & 6.1 & 38.6 & 44.7 \\
\hline
\end{tabular}




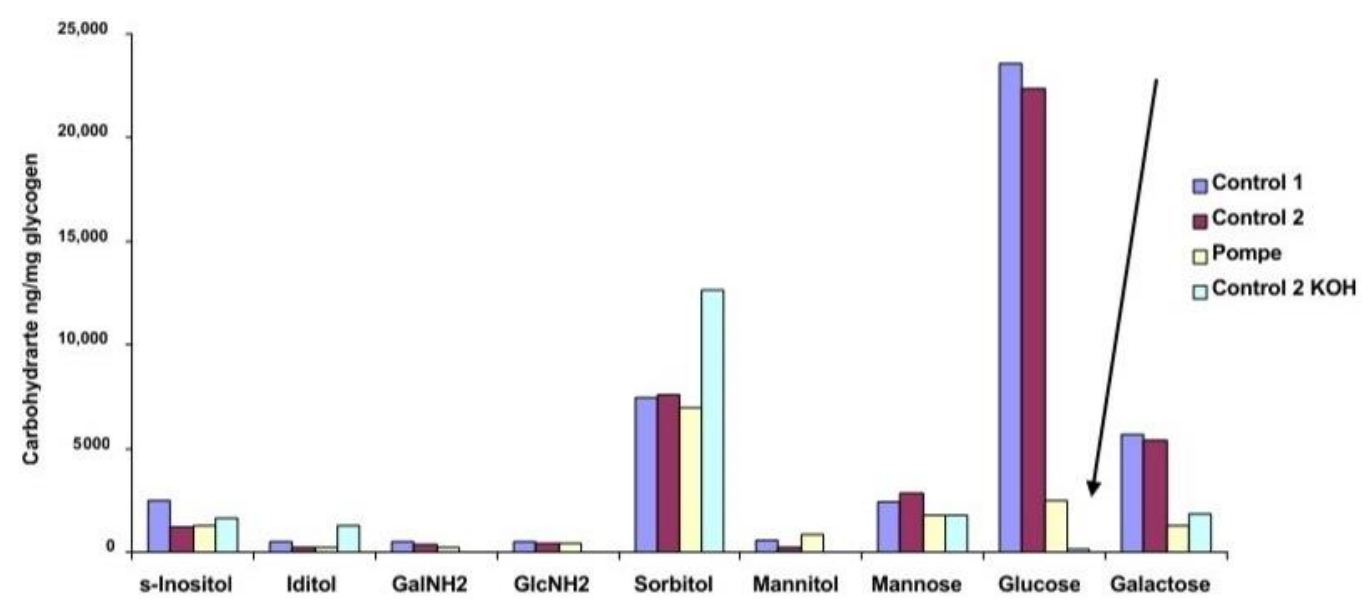

Figure 5. Partial carbohydrate composition of residue from degradation of glycogen by rhGAA. The arrow is to point out the greatly reduced quantity of glucose in Pompe and $\mathrm{KOH}$-treated Control 2 glycogens.

If the glycogens are degraded with amyloglucosidase, a similar residue with a similar carbohydrate composition to that following degradation with rhGAA. It is clearly due to the presence of saccharide residues other than $\alpha$-glucans and the protein. A similar residue with a similar carbohydrate composition remains following amyloglucosidase degradation of corn starch.

The inability of amyloglucosidase to completely digest glycogen is interesting since there are a number of publications which claim that amyloglucosidase completely degrades glycogen [31-35]. In some cases, investigators compared the amount of glucose released by the enzyme to the amount of glucose released by acid hydrolysis but in other cases it appears that they reached that conclusion based on the specificity of amyloglucosidase and the assumption that glycogen only contains glucose. It is clear that these earlier investigators were of the belief that glycogen is composed completely of glucose; therefore, they did not consider other monosaccharide components. Yet, insoluble residue is obvious from visual inspection of the incubation tubes after removal of the incubation medium. From the report of Jeffrey et al. that there is residual material present following degradation of glycogen by rhGAA and isolated lysosomal $\alpha$-glucosidase [7].

\subsection{Treatment of Glycogen Residues with Amyloglucosidase and $\alpha$-Mannosidase}

The residues were treated sequentially with $\alpha$-mannosidase and amyloglucosidase as shown in Figure 6A,B. Treatment with amyloglucosidase followed by $\alpha$-mannosidase did not affect the glucose content of the residues. However, when the residues were treated first with $\alpha$-mannosidase then amyloglucosidase there was a partial reduction in mannose and a significant reduction in both glucose and galactose. Therefore, it appears that part of the mannose impairs access to glucose and galactose by the amyloglucosidase.

On degradation of glycogen by rhGAA most of the glycogen is degraded to glucose. Figure 7A shows oligomers extracted from two different glycogens by boiling in $0.1 \mathrm{~N}$ $\mathrm{HCl}$ before and after the extracts were incubated with (rhGAA). Figure 7B shows the $\mathrm{HCl}$ extract of Control 2 glycogen and corn syrup, a starch hydrolyzate, before and after incubation with rhGAA. Figure 7C shows the oligomers from two glycogens and the maltooligosaccharides from corn syrup after incubation with rhGAA. The corn syrup was Karo syrup (1:100). The similarity of the rhGAA residues of the two glycogens and corn syrup is apparent. The similarity of these rhGAA residues to the rhGAA residues of rabbit limit dextrin and Pompe disease glycogen is shown in Figure 7D. This residual material following glycogen degradation with rhGAA contains about 30 to $40 \%$ protein conjugated to inositols, iditol, sorbitol glucosamine galactosamine mannose glucose and galactose as shown earlier. The co-chromatography of the individual minor peaks for each major peak 
in the Sigma glycogen, Control 2 glycogen and corn starch hydrolyzates in these is taken as evidence that the glycogen residue is not a contaminant of glycogen.

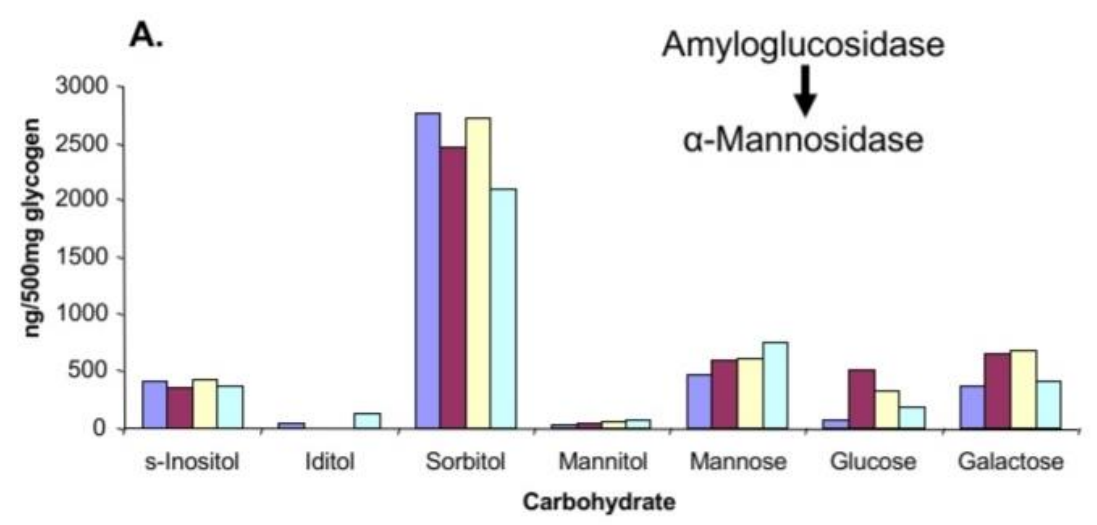

$\square$ Sigma Res AG/?-M

- Control 1 Res AG/?-M -Control 2 Res AG/?-M $\square$ Pompe Res AG/?-M

B.

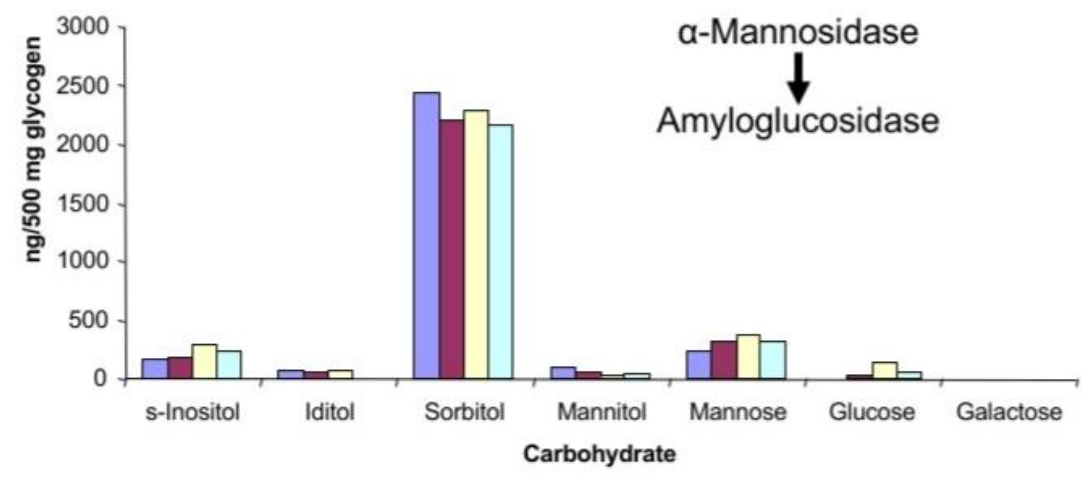

口Sigma Res ?-M/AG

- Control 1 Res ?-M/AG

口Control 2 Res ?-M/AG

$\square$ Pompe Res ?-M/AG

Figure 6. (A). Glycogen degradation residues treated with amyloglucosidase followed by $\alpha$ mannosidase. (B). Glycogen degradation residues treated with $\alpha$-mannosidase followed by amyloglucosidase. Residues were incubated with either amyloglucosidase of $\alpha$-mannosidase for $24 \mathrm{~h}$ at $37^{\circ} \mathrm{C}$ at $\mathrm{pH} 4.5$ and then switched to the other enzyme as indicated.

\subsection{Glycosylated Protein Biomarkers}

The subjects of a previous paper were the glucan and a glycosylated protein which is glycosylated primarily with inositol and sorbitol [36]. The enzyme releases about $70-75 \%$ of the glycogen as glucose by the action of rhGAA in vitro. After about four days of incubation of glycogen with rhGAA in vitro, the released glucose reaches a plateau, thus no more glucose is released. There is no detectable carbohydrate in the medium that elutes after glucose by HPAEC-PAD employing a CarboPac PA1 column. However, if the medium is boiled in $0.1 \mathrm{~N} \mathrm{HCl}$ for $30 \mathrm{~min}$, several oligosaccharides are detected. The oligosaccharides are also detected after incubation of the medium with trypsin. This appears to be a case of protein masking carbohydrate which is unusual but has been reported [37,38]. The soluble glycosylated protein in the medium is bound by Dowex 50W. This is taken as evidence of binding by a charged entity such as protein. The soluble glycosylated protein is not bound by Concanavalin A which binds mannose or glucose containing carbohydrates, including glycogen [36]. Given these characteristics the possibility of lysosomal exocytosis, serum was analyzed, and the soluble glycosylated protein was found.

The comparison of their chromatographic identity of the glycosylated protein end product which cannot be further degraded by rhGAA and the glycosylated protein from serum are shown in Figure 8 taken from Murray [36]. In addition, the carbohydrate of this biomarker, which is labeled 2-2, is shown in Figure 9 [36]. The other glycosylated proteins for which the carbohydrate composition is shown are under investigation to increase our understanding of these masked glycosylated proteins. 
A.

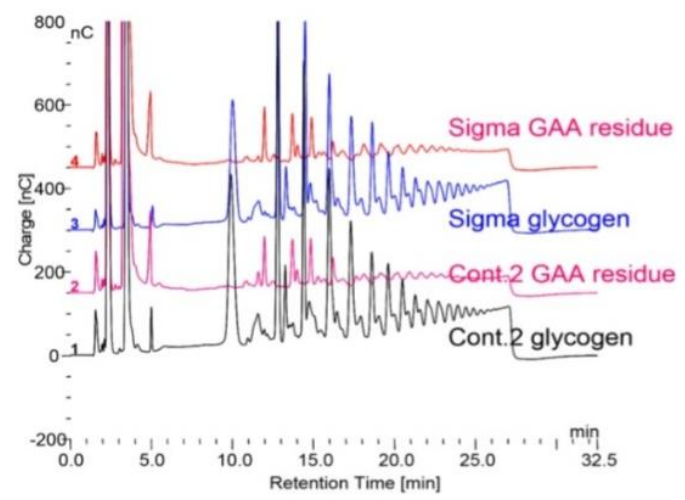

B.

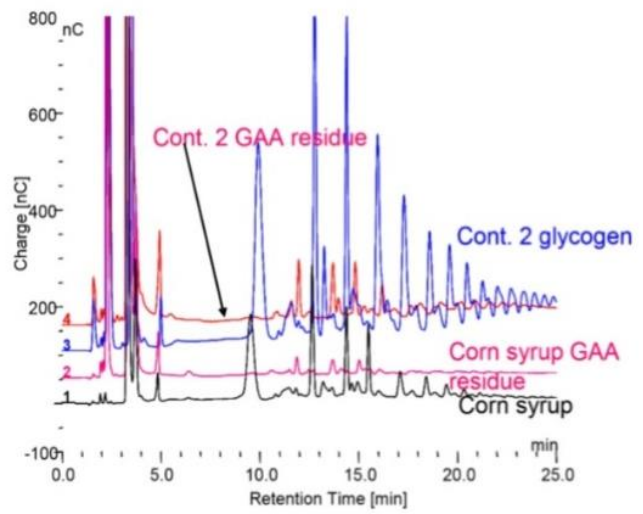

C.

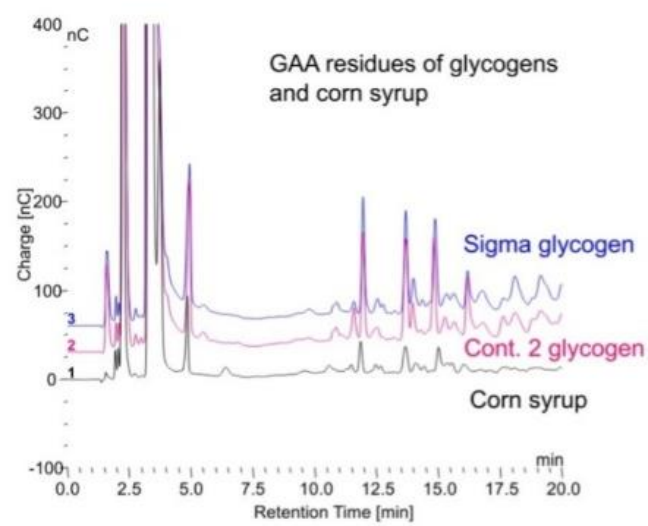

D.

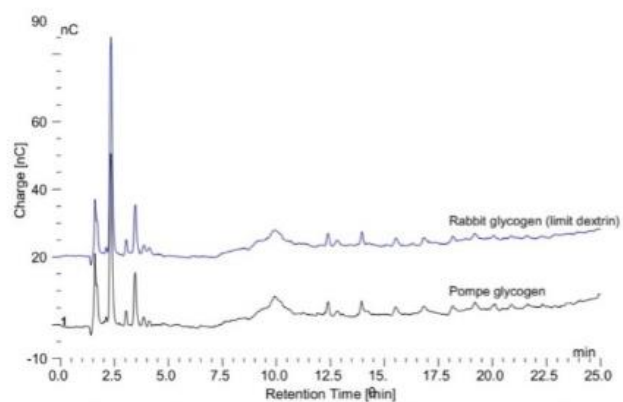

Figure 7. (A) Sigma and Control 2 glycogen $\mathrm{HCl}$ extracts and their residues following rhGAA degradation, (B) Control $2 \mathrm{HCl}$ extract and corn syrup oligosaccharides and their residues following rhGAA degradation, (C) Sigma, Control 2 and corn syrup residues following rhGAA degradation, (D) Pompe glycogen and rabbit limit dextrinh residues following rhGAA degradation.

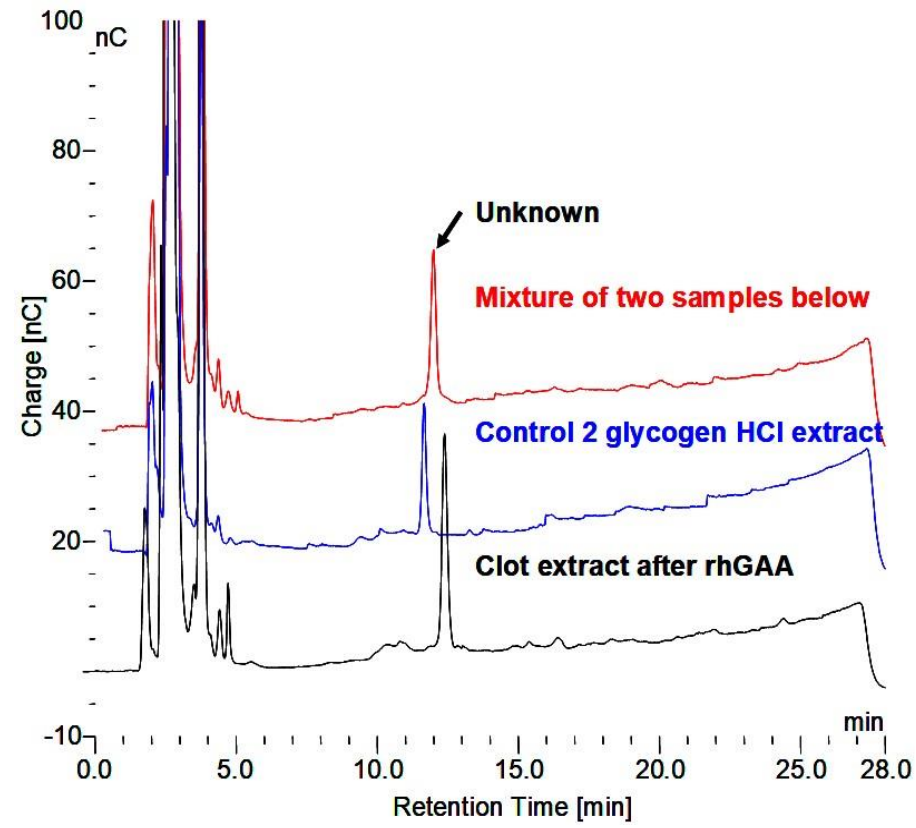

Figure 8. Clot $\mathrm{HCl}$ extracted after degradation with rhGAA demonstrates the unknown is not degraded. $\mathrm{HCl}$ extract of Control 2 glycogen, $\mathrm{HCl}$ extract following rhGAA degradation and a mixture of equal parts of both extracts demonstrating one symmetrical peak. Reprinted from Murray [36]. 


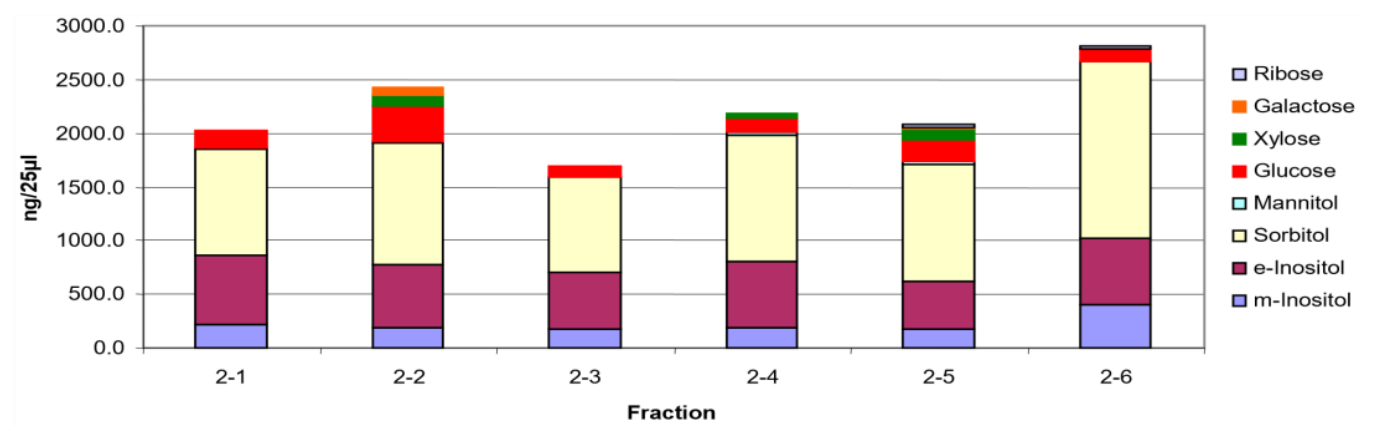

Figure 9. Monosaccharide composition of fractions. Fraction 2-2 is the biomarker of interest. Reprinted from Murray [36].

Based on the carbohydrate composition of the fractions, the major components are the two inositols, sorbitol and mannitol are similar with variability in the hexose occurrence. It is important to be mindful these are the monosaccharide compositions of oligosaccharides which still contain peptide. Following incubation with rhGAA, all of them except 2-2 are converted increasing 2-2 and glucose. This suggests that glucose is a critical constituent even though it is quantitatively a minor constituent. At least some of the others appear to be converted to 2-2. However, they all contain peptide, but it is unknown if it is the same for all of them. Therefore, it is not possible to determine quantitative relationships. Based on more recent work, it is likely that there are multiple glycosylation sites with different monosaccharide composition involved.

The carbohydrate composition of these soluble glycosylated proteins is unique by consisting mainly of inositols and sorbitol with some iditol. Literature searches do not reveal any glycosylated proteins published with these as the major carbohydrate. In fact, a search does not reveal any publication of a glycosylated protein with sorbitol.

The biomarker glycosylated protein, found in normal individuals, is present in the serum of Pompe patients who are on ERT but it is not present in the serum of Pompe mice that are not on ERT as shown in Figure 10. The Pompe mice not on ERT do have another glycosylated protein present in the serum which elutes at about 18 min retention time, which is not present in the serum of Pompe patients on ERT or normal individuals as shown in Figure 10. It is possible that his peak may be a biomarker for Pompe disease. This potential biomarker for Pompe disease was collected and incubated with trypsin and chymotrypsin as shown in Figure 11A. The peaks were collected as shown in Figure 11B, hydrolyzed in 4 N TFA and the monosaccharides are shown in the chromatograms in Figure 11C. The result of this preliminary analysis is the demonstration that there are multiple glycosylation sites on the protein and that the monosaccharide composition of each glycosylation site is different. A similar result was obtained for the biomarker for GAA degradation. These results indicate that it will not be a simple task to determine the relationship between all of these glycosylated peptides.

The investigation of these glycosylated proteins is complicated by the fact that they the carbohydrate is masked and then unmasked by $0.1 \mathrm{~N} \mathrm{HCl}$ at $100^{\circ} \mathrm{C}$ then masked after dialysis against water. The biomarker at about $11 \mathrm{~min}$ and the other peak at $18 \mathrm{~min}$ in Figure 10 are present after the $\mathrm{HCl}$ treatment. The five other oligosaccharides in Figure 10 and the ones in Figure 11 are all present after digestion with proteases. Therefore, it is not known just how many glycosylated proteins are involved. It could be as few as two and it is possible that they may be related since one is present when there is GAA activity in vivo and the other is present in the absence of GAA in vivo. The protein originates in glycogen, but it does not appear to be a known protein and the glycosylation is very unusual given the inositol, sorbitol and sometimes iditol. 


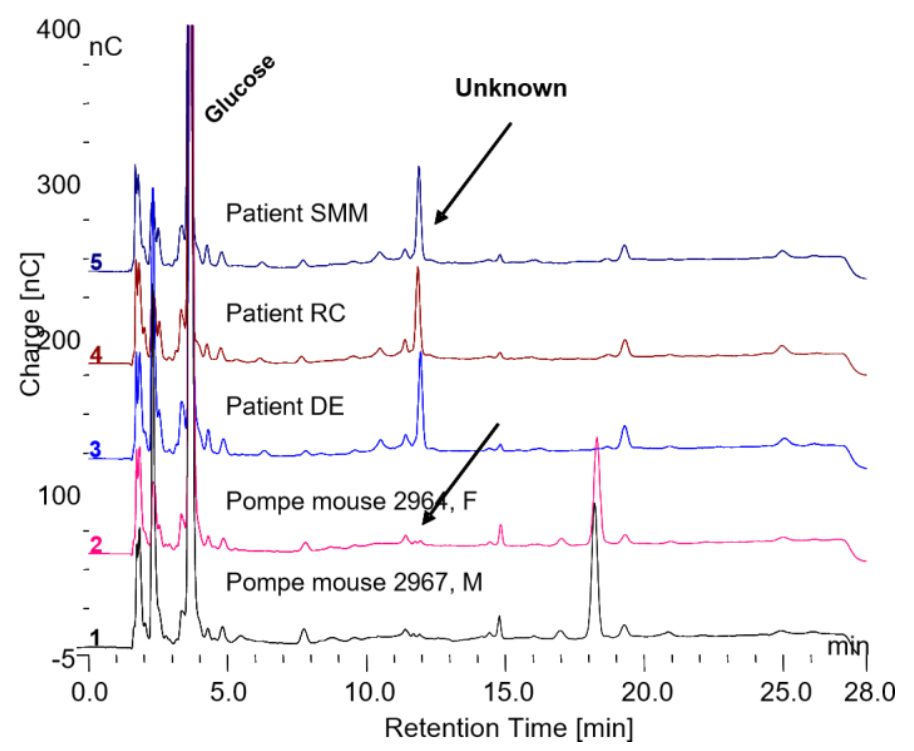

Figure 10. The $0.1 \mathrm{~N} \mathrm{HCl}$ extracts of serum, 1:10 from two Pompe mice, age 8.7 months and three Pompe patients. The peak at about $18 \mathrm{~min}$ in the Pompe mouse serum is a glycosylated protein containing m-inositol, sorbitol and glucose as major components as well as galactose and mannose. It is further described in Figure 11. Reprinted from Murray [36].
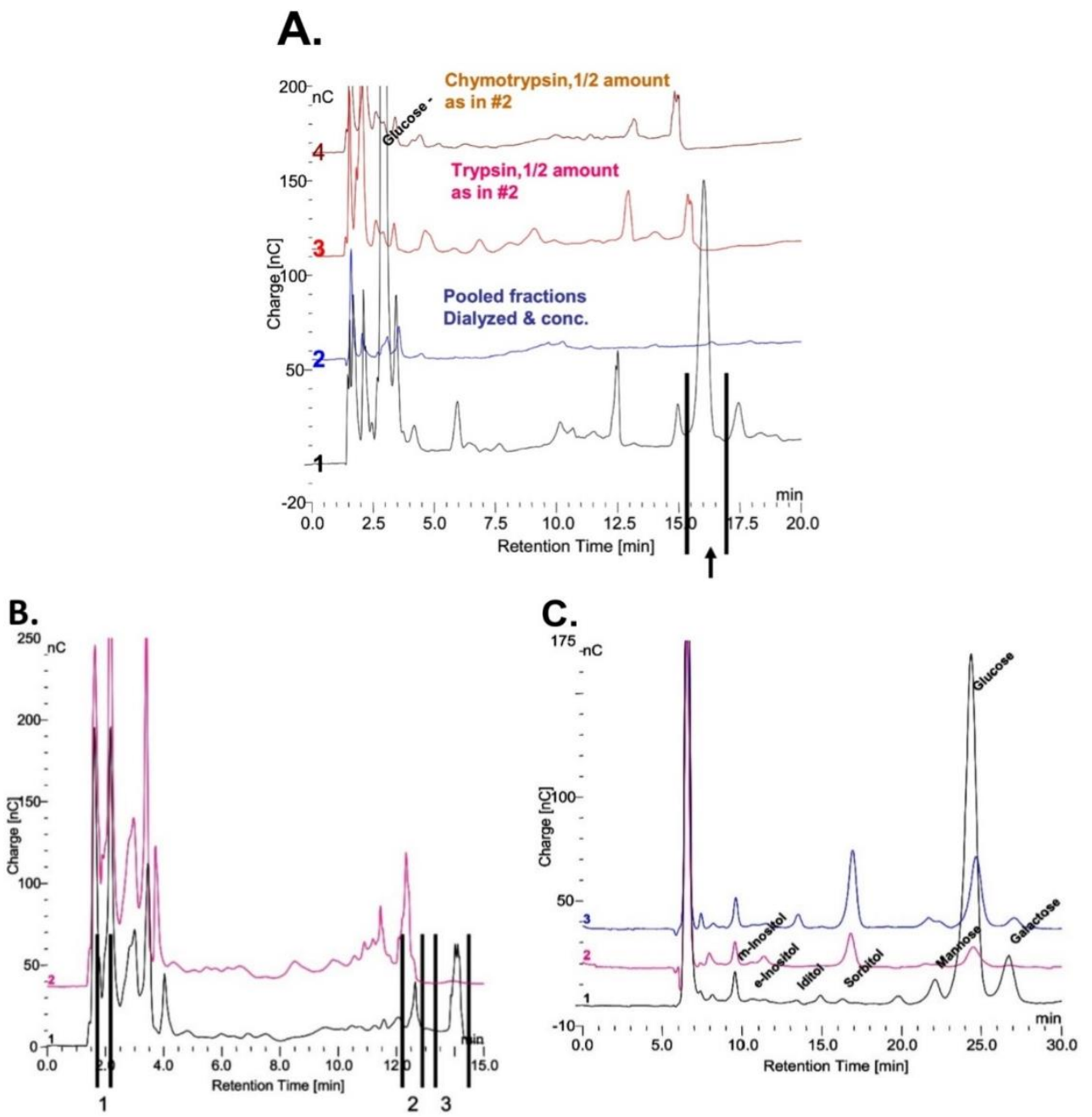

Figure 11. (A) Fractions collected from $\mathrm{HCl}$ extract of Pompe mouse serum. (B) Pooled and dialyzed factions 1-3 collected. (C) Monosaccharides in fractions 1-3. 
The question of whether these in vivo fractions are intact components of glycogen or whether they have undergone some modification by GAA, or any other enzymes, is an open question since GAA does have glucanase, glucantransferase and glucosyltransferase activities under the same conditions in which it has glucosyl hydrolase activity [7-10]. As discussed earlier there is a commonly held belief that GAA only breaks glycogen down to glucose, but it breaks down glycogen to some oligosaccharides which then are later degraded to glucose as well as the glycosylated proteins.

\section{Discussion}

\subsection{Glycogen Structure Is the Basis for Metabolomics}

A detailed description of the current model for glycogen is presented in the review by Roach et al. [1,2]. The key points of the model for the glycogen molecule or particle are that it consists of $\alpha-1,4$ linked glucans and that at an average of every 12 residues there is an $\alpha-1,6$ linkage for a branch point. There are outer branches and inner branches referred to as A chains and B chains, respectively. Illingworth et al. [39] determined the chain length of the glucans. The Whelan model proposed by Gunja-Smith et al. [40] takes into account the information available at that time. The Whelan model [40] has been validated by considerable work on maltoheptaose and calculations by Goldsmith et al. [41]. Further, Kirkman and Whelan [42] reported that glycogen also contains glucosamine. At the core is the self glucosylating protein, glycogenin, which is the primer for biosynthesis [1]. The first glycosylation position on glycogenin may contain xylose [43]. It would seem that there may be an additional level of organization of complex structure in addition to that proposed to account for the differences between different glycogens shown in Figure 3. It does not seem likely that the differences in inner and outer chain lengths of the glycogens, as described in the materials and methods, would account for the differences shown in Figure 3. It would appear that the difference in glucose content of the rhGAA-treated Pompe glycogen residue and $\mathrm{KOH}$-treated Control 2 glycogen residue and the Control glycogen residues in Figure 5 are likely due to differences in the complexity or configuration of the glycogen structure since the glucose content of the glycogen residue of the $\mathrm{KOH}$-treated Control 2 glycogen is very low compared with the Control 2 glycogen. Additional work on the glycosylated protein which is the portion of glycogen which cannot be degraded by rhGAA is essential.

The glycosylated protein described in this report should not be confused with glycogenin. It should be pointed out that glycogenin and the glycosylated protein appear to occupy different points of attachment to the polysaccharide. Glycogenin is attached to the reducing end of glycogen [1]. The glycosylated protein in this work is found associated with each oligosaccharide derived from the polysaccharide whether released by weak acid or enzymatic hydrolysis. The glycosylated protein associated with each oligosaccharide must differ in carbohydrate composition to account for their chromatographic separation; however, they could differ by a repeating unit. This implies that they likely are associated along the length of the polymer, whereas glycogenin is attached at the nonreducing end and they are present in isolated oligosaccharides.

\subsection{Observations Not Accounted for by the Glycogen Model}

The model does not account for a glycosylated protein associated with oligosaccharides containing myo-inositol, scyllo-inositol, epi-inositol, iditol, sorbitol, galactosamine, glucosamine, mannose, glucose and galactose identified in this present work. These results not only raise questions about the degradation of glycogen but also raise questions about the biosynthesis and structure of glycogen. The current paradigm is that glycogenin is an autocatalytic protein which is self-glucosylating up to 20 glucose residues which then go on to function as the primer for glycogen synthase. However, there is now the complicating fact that the glycogen particle has glucose accessible to enzymatic degradation by $\alpha$-glucosidase and presumably phosphorylase and debrancher. At some point there is an entity which it is not susceptible to further $\alpha$-glucosidase degradation which contains other hexoses and sugar alcohols as well as protein. There are a number of proteins known to be 
associated with glycogen and there is data to indicate that pro-glycogen, macroglycogen and lysosomal glycogen all differ in amount of protein(s) associated with them, but the known proteins associated with glycogen have not been shown to be covalently linked to glycogen except for glycogenin [1]. The question becomes one of the possibilities of some precursor with which the nascent glycogen particle may become associated at some early stage in biosynthesis. The precursor(s) would possibly be synthesized concomitantly with the growing glucan chains. The precursor carbohydrate composition would vary with the oligosaccharide length. The glycosylated proteins appear to be small and associated with the monosaccharides, thus it would appear to be concomitantly synthesized and or incorporated.

GAA degrades glycogen to oligosaccharides and then degrades the oligosaccharides to glucose. There is a cytoplasmic $\alpha$-glucosidase with a $\mathrm{pH}$ optimum of 7.1, which has both $\alpha-1,4$ and $\alpha-1,6-$ glucosidase activities, which is present in liver and muscle which degrades oligosaccharides to glucose, but it does not act on glycogen [44]. The evidence that the glycosylated protein is not a contaminant is shown in Figure 7. Analogous or identical glycosylated proteins are present in corn starch and cellulose. The glycosylated proteins from glycogen and starch hydrolyzate co-chromatograph on HPAEC-PAD. The same material is present in commercially obtained maltooligosaccharides and cellooligosaccharides.

\subsection{Deficiency in Pompe Disease}

GAA deficiency is the cause of Pompe disease, but some process other than GAA hydrolysis must participate in the degradation of lysosomal glycogen. It is known that all lysosomes do not contain all of the known lysosomal enzymes. From the results of Jeffrey et al. [7] and the results presented here it is clear that the cause cannot be as simple as a deficiency of GAA hydrolysis since it cannot completely degrade glycogen. Brown et. al., in their elegant study of glycogen degradation in debrancher deficient fibroblasts, investigated glycogen degradation by the lysosomal pathway [45]. They concluded that the lysosomal degradation of glycogen only proceeded at about $1 \%$ of the rate of glycogen degradation by the lysosomal $\alpha$-glucosidase under optimal conditions [40]. As a result, they reasoned that the rate limiting step is the incorporation of autophagic vesicles containing glycogen fusing with primary lysosomes. More recently, the importance of autophagy in glycogen degradation and Pompe mouse tissues has been demonstrated by Raben et al. [46]. It is also clear from the results of Jeffrey et al. [7] and the residue described here that we do not know how lysosomal or cytoplasmic glycogen is completely degraded since phosphorylase and debrancher did not completely degrade Pompe glycogen after rat liver lysosomal $\alpha$-glucosidase degradation. It should be noted that Jeffrey et al. [7] found that about $5 \%$ of the glycogen could not be degraded by the enzymes used. Rabbit muscle lysosomal $\alpha$-glucosidase was found to degrade rabbit liver glycogen and shellfish glycogen $\beta$-limit dextrin by $95 \%$ and shellfish glycogen and shellfish phosphorylase-limit dextrin by $100 \%$ [9]. However, it is not stated how this calculation was carried out but earlier work in that laboratory determined the extent of degradation by comparison of glucose released by the enzyme to glucose released by acid hydrolysis [9]. However, the acid may have been strong enough to release the glucose but not the other components since the minor constituents are significantly more resistant to acid hydrolysis than the glucan [24]. The $\alpha$-glucosidase resistant residue reported here has been found in glycogen from human tissue as well as bovine, rabbit and oyster also consist of about 4 to $6 \%$ of the total glycogen. It is likely to be similar to or identical to the soluble glycosylated protein from glycogen found in serum [36].

\subsection{Glycogen Determination}

The use of amyloglucosidase to degrade glycogen to glucose for the determination of the glycogen content of biological samples is the most common method used. There are a number of publications reporting glycogen determination using amyloglucosidase and there are over 80 publications which refer to the complete degradation of glycogen 
by amyloglucosidase. However, those reporting complete degradation base that statement on the comparison of glucose released by amyloglucosidase with glucose released by acid hydrolysis. These reports typically involved the enzymatic determination of the glucose released [32-36]. The alditols and hexoses found in the GAA resistant residue were also found in TFA hydrolyzates of glycogen, maltooligosaccharides and cellooligosaccharides [24]. In the case of another polysaccharide, cellulose, following hydrolysis in $6 \mathrm{~N}$ $\mathrm{HCl}$ six oligosaccharides that release amino acids on further acid hydrolysis with TFA, with similar carbohydrate compositions were also found [24]. These results suggest that all three glucans, glycogen, starch and cellulose may have a very similar component of a glycosylated protein.

One problem with a number of publications on Pompe disease is with the glycogen determination on mouse tissues in reports on ERT. Glycogen is a polysaccharide consisting of different sizes of glycogen particles. In the analysis of tissues, the tissue homogenate is centrifuged prior to the amyloglucosidase incubation to release glucose. The centrifugation steps used in glycogen determinations in publications varies from about $1500 \times g$ to $18,000 \times g$. Therefore, clearly all of the work is not measuring the same thing and calling it glycogen. A number of papers simply describe glycogen determination of glucose released by amyloglucosidase without giving details but often citing a reference. Unfortunately, the reference cited does not mention the centrifugation step in detail. Therefore, the result is a large number of published papers in which the complete glycogen procedure is not described. Given the nature of glycogen and the possibility of boiling extracts before centrifugation precipitating even more glycogen, as mentioned by Brown et. al, results in ambiguity about the quantification of glycogen [40]. It would also be informative to have the time between sacrifice of the animal and analysis, freezing or whatever means of stopping degradation is used. This is because glycogen is rapidly degraded after death and the degradation is not uniform among different sizes of glycogen and greater in the higher molecular weight glycogen $[29,47]$. With respect to comparisons of Pompe mice $+/-$ ERT it would also be helpful to see wild type mouse tissue included since that is the goal of ERT. Due to the demonstrated differences in glycogens, it may be informative to include information in addition to just glucose released by amyloglucosidase since glucose released by amyloglucosidase would include oligosaccharides as well.

\subsection{Further Studies on the rhGAA Resistant Residue of Glycogen}

Future work on the rhGAA resistant residue of glycogen will not be performed on the material described here because it is now known that this material is a mixture of residues since there is a different one associated with each oligosaccharide. For this reason, individual fractions of the residue will be isolated by HPAEC-PAD, collected and analyzed separately since they must differ in carbohydrate composition to account for their separation on HPAEC-PAD as shown in Figure 7 although they may differ by a repeating unit [24]. These fractions will also be analyzed by mass spectrometry for the protein component and protein-carbohydrate linkage analysis.

\subsection{Biomarkers}

The biomarker identified in Figures $8-10$ is an indicator of glycogen degraded by GAA, thus its use to monitor ERT will be investigated to determine the optimal frequency and dose for enzyme infusions. In addition, the large peak in the serum of Pompe mice not on ERT in Figures 10 and 11 appears to be a biomarker for Pompe disease and will be investigated for such application.

It should be pointed out that there is a putative urinary biomarker for Pompe disease Glc 4 or Hex 4 which is a tetrasaccharide of glucose, Glc- $\alpha-1,6-G l c-\alpha-1,4-G l c-\alpha-1,4-G l c$. This biomarker was first published in 1974 and it is the subject of many publications since then but its metabolic origin has not been definitively determined [48]. This work described action of salivary amylase and serum $\alpha$-glucosidase on glycogen. As a result of the present work, I would question the commercial glycogen used as it may be degraded somewhat to 
begin with. Additionally, in this case of this biomarker it is not clear where the glycogen would come into contact with the serum $\alpha$-glucosidase. Their mention of total body content of $30 \mathrm{~g}$ of glycogen is very far from other estimates at close to $1200 \mathrm{~g}$ total body glycogen.

\subsection{Enzyme Specificity Hydrolase and Transferase}

All of the activities of GAA are required to degrade the glucosidic components of glycogen. For this reason, it is important to remember that it is not possible to try to extrapolate from the activity on a simple substrate such as the 4-methylumbelliferyl glucoside or the $p$-nitrophenyl glucoside to estimate the activity of the enzyme on glycogen. A glycosyl hydrolase is simply a specific case of a glycosyltransferase using water as the acceptor alcohol. With the artificial substrates the detection is only measuring the aglycone; therefore, the fate of the glucose is unknown. For example, when investigating a cell wall bound $\beta$-glucosidase, since a labeled substrate was not available, I synthesized $p$-nitrophenyl- $\beta$-D- ${ }^{14} \mathrm{C}$-glucose for the substrate and determined that a significant portion of the glucose was incorporated into a product in the cell wall preparation that was then extracted with oxalic acid and isolated as a disaccharide [49].

\subsection{Proposed Lysosomal Pathway}

Is it possible that the components of all glycogen could ultimately be degraded via the lysosomal pathway? The very careful work of Brown et al. with cultures fed ${ }^{14} \mathrm{C}$ and ${ }^{3} \mathrm{H}$ labeled glucose to label the glycogen in debrancher deficient fibroblasts demonstrated the degradation of glycogen via the lysosomal route [40]. Since the cells were lacking debrancher only the outer branches could be degraded by phosphorylase; therefore, the remainder had to be degraded via the lysosomal pathway. From the results presented here the components of glycogen which cannot be degraded by rhGAA would not be expected to be degraded by phosphorylase and debrancher either. Pompe glycogen which was degraded $80 \%$ by GAA and then incubated with phosphorylase and debrancher was not completely degraded [7].

The biomarker detector response calculated for $1 \mathrm{~g}$ of glycogen was $667,728 \mathrm{nC} * \mathrm{~min}$. Using generally accepted values for muscle and liver weight for a $175 \mathrm{lb}$ man and generally accepted values for the proportion of muscle (75\%) and liver (1000 g) and 2\% for muscle and $5 \%$ for liver the body content of glycogen it is estimated at $1260 \mathrm{~g}$. Lysosomal glycogen is about $2 \%$ of total glycogen which would be $25.2 \mathrm{~g}$. The three-day average of multiple determinations detector response for a 1:10 dilution of serum from one individual was $257.7 \mathrm{nC}^{*} \mathrm{~min} / \mathrm{mL}$. For a blood volume of $6000 \mathrm{~mL}$ this value was the calculated value for $46.3 \mathrm{~g}$ glycogen. These are rough numbers with a number of assumptions. Considering that most of the glycogen may be what was not degraded by phosphorylase and debrancher, the rate of degradation of the biomarker is unknown, the rate of glycogen entering the cellular and lysosomal environment is unknown and such it is quite remarkable that the numbers are even within an order of magnitude of each other. The only reason for this crude approximation was to determine if the numbers might be close enough to even consider the possibility. I think it is worth considering the possibility. Further work on the biomarker, investigation of serum of Pompe patients, control patients and endurance athletes, in particular, may further demonstrate if this possibility is reasonable.

The potential downside of this proposal comes from the very nice work of Calder and Geddes $[30,48]$. They determined that lysosomal glycogen is of higher molecular weight than the cytoplasmic glycogen. Given the technological advances, such as HPAEC-PAD, since the time that work was carried out it would be important to repeat the comparison of lysosomal glycogen with cytoplasmic glycogen and determine the carbohydrate and protein composition of both. As indicated by results presented here, the determination of glycogen by glucose released by amyloglucosidase may not tell the whole story. Based on the possibility, I have proposed a potential pathway in Figure 12. 


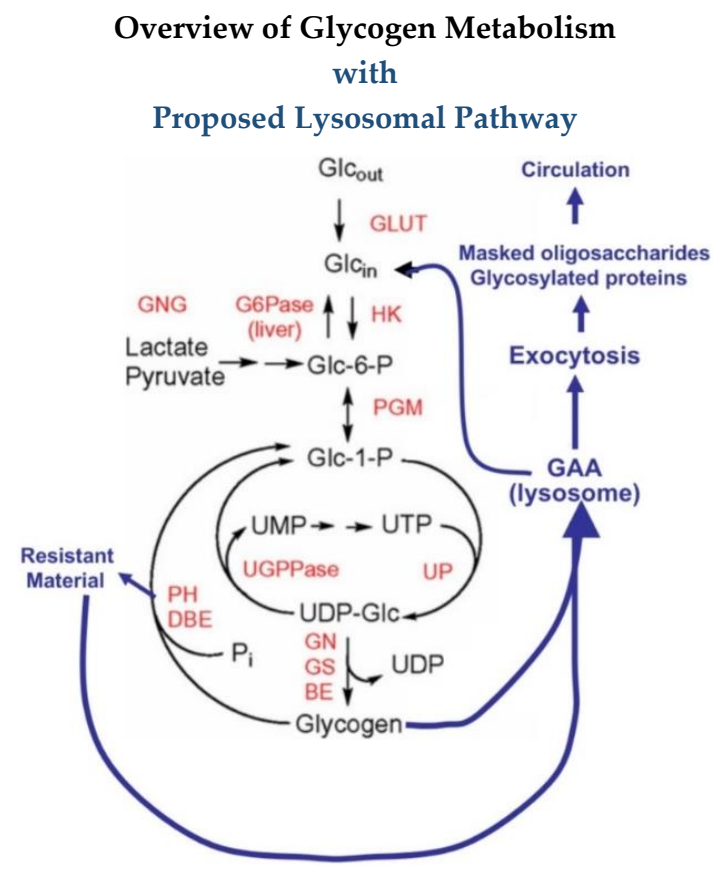

Figure 12. Proposed addition (blue) to overview of glycogen metabolism Glc $\mathrm{cut}_{\text {, }}$ extracellular glucose;

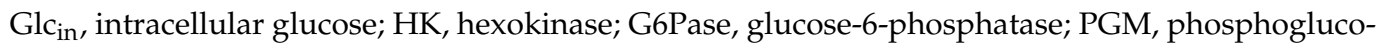
mutase; UP, UDP-glucose pyrophosphorylase; UGPPase, UDP-glucose pyrophosphatase; GN, glycogenin; GS, glycogen synthase; BE, branching enzyme; $\mathrm{PH}$, glycogen phosphorylase; DBE, debranching enzyme; GAA, lysosomal $\alpha$ glucosidase; GNG, gluconeogenesis. Adapted from Roach et al. [1].

\section{Conclusions}

1. There are differences between glycogens from different sources and different preparations that are reflected in their degradation rates by rhGAA. These are differences in the complexity of the glycogen which shows that the number of glycosyl linkages which must be cleaved to release a glucose residue vary within the glycogen particle.

2. Glycogen cannot be completely degraded by either amyloglucosidase or rhGAA due to the presence of constituents other than glucose, a glycosylated protein component.

3. The residual material that cannot be degraded by rhGAA consists of glycosylated proteins associated with oligosaccharides in acid hydrolyzates of glycogen. The glycosylation of the proteins is unusual. The major carbohydrates are inositols, iditol, sorbitol, glucosamine, galactosamine mannitol, mannose, glucose and galactose.

4. The carbohydrate composition of the residual material is similar to that of the soluble glycosylated protein identified earlier which is also found in serum and appears to be a biomarker for GAA degradation of glycogen.

5. A similar glycosylated protein present in the serum of Pompe mice not on ERT may be a biomarker for Pompe disease.

Funding: This work was supported by a grant from Sanofi Genzyme GZ-2015-11412 and GZ-2017-11679.

Institutional Review Board Statement: The IRB approval was UC Irvine, UCI/2008-6631.

Informed Consent Statement: Informed consent was obtained from all subjects involved in this study.

Acknowledgments: I would like to thank Virginia Kimonis for serum samples from Pompe mice and human Pompe patients on ERT.

Conflicts of Interest: The author declares no conflict of interest. 


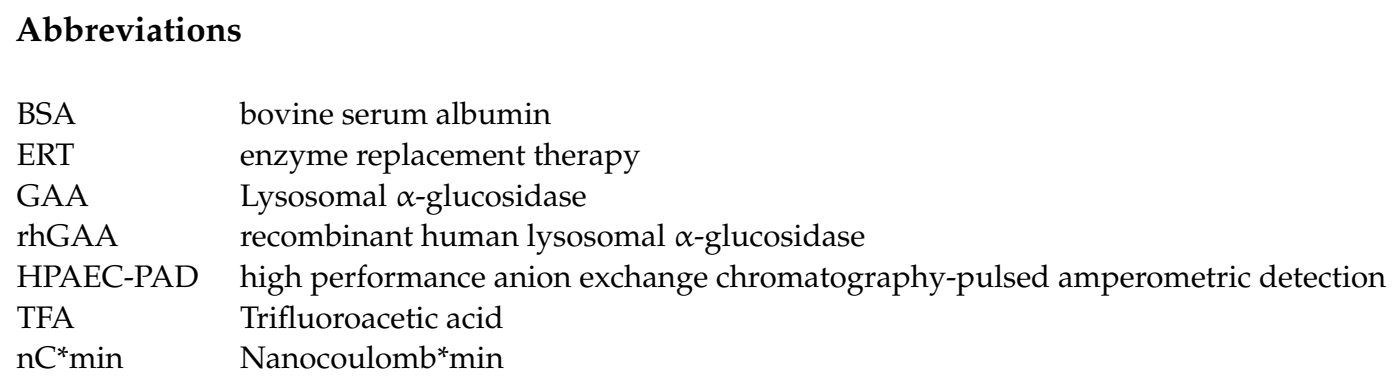

\section{References}

1. Roach, P.J.; DePaoli-Roach, A.A.; Hurley, T.D.; Tagliabracci, V.S. Glycogen and its metabolism: Some new developments and old themes. Biochem. J. 2012, 441, 763-787. [CrossRef] [PubMed]

2. Melendez-Hevia, E.; Waddell, T.G.; Shelton, E.D. Optimization of molecular design in the evolution of metabolism: Glycogen molecule. Biochem. J. 1993, 295, 477-483. [CrossRef]

3. Prats, C.; Graham, T.E.; Shearer, J. The dynamic life of the glycogen granule. J. Biol. Chem. 2018, 293, 7089-7098. [CrossRef]

4. Hers, H.G. $\alpha$-Glucosidase deficiency in generalized glycogen-storage disease (Pompes disease). Biochem. J. 1963, 86, 11-16. [CrossRef]

5. Torres, H.N.; Olavarria, J.M. Liver $\alpha$-Glucosidases. J. Biol. Chem. 1964, 239, 2427-2434. [CrossRef]

6. Brown, B.I.; Brown, D.H.; Jeffrey, P.L. Simultaneous Absence of $\alpha-1,4$-Glucosidase and $\alpha-1,6-$ Activities (pH4) in Tissues of Children with Type II Glycogen Storage Disease. Biochemistry 1970, 9, 1423-1428. [CrossRef]

7. Jeffrey, P.L.; Brown, D.H. Brown, B.I. Studies of Lysosomal $\alpha$-Glucosidase. I. Purification and properties of the Rat Liver Enzyme. Biochemistry 1970, 9, 1403-1415. [CrossRef]

8. Jeffrey, P.L.; Brown, D.H.; Brown, B.I. Studies of Lysosomal $\alpha$-Glucosidase. II. Kinetics of the Rat Liver. Biochemistry 1970, 9 , 1416-1422. [CrossRef]

9. Palmer, T.N. The substrate specificity of acid $\alpha$-glucosidase from rabbit muscle. Biochem. J. 1971, 124, 701-711. [CrossRef]

10. Palmer, T.N. The Maltase, Glucamylase and Transglucosylase Activities of Acid $\alpha$-Glucosidase from Rabbit Muscle. Biochem. J. 1971, 124, 713-724. [CrossRef]

11. Hers, H.G.; van Hoof, F. Enzymes of Glycogen Degradation in Biopsy Material. Methods Enzymol. 1966, 8, 525-532.

12. Bijvoet, A.G.A.; van de Kamp, E.H.M.; Kroos, M.A.; Ding, J.-H.; Yang, B.Z.; Visser, P.; Bakker, C.E.; Verbeet, M.T.; Oostra, B.A.; Reuser, A.J.J.; et al. Generalized glycogen storage and cardiomegaly in a knockout mouse model of Pompe disease. Hum. Mol. Genet. 1998, 7, 53-62. [CrossRef]

13. Koeberl, D.D.; Luo, X.; Sun, B.; McVie-Wylie, A.; Dai, J.; Li, S.; Banugaria, S.G.; Chen, Y.-T.; Bali, D.S. Enhanced Efficacy of Enzyme Replacement Therapy in Pompe Disease Through Mannose-6-Phosphate Receptor Expression in Skeletal Muscle. Mol. Genet. Metab. 2011, 103, 107-112. [CrossRef]

14. Raben, N.; Fukuda, N.; Gilbert, A.L.; de Jong, D.; Thurberg, B.L.; Mattaliano, R.J.; Meikle, P.; Hopwood, J.J.; Nagashima, K. Replacing Acid $\alpha$-Glucosidase in Pompe Disease: Recombinant and Transgenic Enzymes are Equipotent, but Neither Completely Clears Glycogen from Type II Muscle Fibers. Mol. Ther. 2005, 11, 48-56. [CrossRef]

15. Xu, S.; Lun, Y.; Frascella, M.; Garcia, A.; Soska, R.; Nair, A.; Ponery, A.S.; Schilling, A.; Feng, J.; Tuske, S.; et al. Improved efficacy of a next-generation ERT in murine Pompe disease. JCI Insight 2019, 4, e125358. [CrossRef]

16. Del Rizzo, M.; Fanin, M.; Cerutti, A.; Cazzorla, C.; Milanesi, O.; Nascimbeni, A.C.; Angelini, C.; Giordano, L.; Bordugo, A.; Burlina, A. Long-term follow-up results in enzyme replacement therapy for Pompe disease: A case report. J. Inherit. Metab. Dis. 2010, 33, 389-393. [CrossRef]

17. Van Der Ploeg, A.; Carlier, P.G.; Carlier, R.-Y.; Kissel, J.; Schoser, B.; Wenninger, S.; Pestronk, A.; Barohn, R.J.; Dimachkie, M.M.; Goker-Alpan, O.; et al. Prospective exploratory muscle biopsy, imaging, and functional assessment in patients with late-onset Pompe disease treated with alglucosidase alfa: The EMBASSY Study. Mol. Genet. Metab. 2016, 119, 115-123. [CrossRef]

18. Salbato, J.; (UC Irvine, Irvine, CA, USA). Pompe patient in initial trial in 2005. Personal Communication, 2021.

19. Williams, J.C.; Murray, A.K. Enzyme replacement in Pompe disease with an alpha-glucosidase-low density lipoprotein complex. Birth Defects. Orig. Artic. Ser. 1980, 16, 415-423.

20. Bell, D.J.; Young, F.G. Observations on the Chemistry of Liver Glycogen. Biochem. J. 1934, 28, 882-889. [CrossRef] [PubMed]

21. Mordoh, J.; Krisman, C.R.; Leloir, L.F. Further Studies on High Molecular Weight Liver Glycogen. Arch. Biochem. Biophys. 1966, 113, 265-272. [CrossRef]

22. De Wulf, H.; Hers, H.G. Paracrystalline Glycogen. In Biochemistry of the GlycosidicLinkage: An Integrated View; Academic Press: Cambridge, MA, USA, 1972; pp. 399-402.

23. Metzenberg, A.B. Structural Feathers of Stored Glycogen in a Case of Pompe's Disease [Glycogenosis Type II]. Master's Thesis, University of California, Irvine, CA, USA, 1980.

24. Murray, A.K.; Metzenberg, A.B.; Nichols, R.L. Polysaccharide Similarities: Glycosylated Protein Cores of Glycogen, Starch and Cellulose; Glycan Technilogies, Inc.: Irvine, CA, USA, 2021; manuscript in preparation. 
25. Lee, E.Y.C. The action of Sweet Potaato $\beta$-amylase on Glycogen and Amylopectin: Form of a Novel Limit Dextrin, Arch. Biochem. Biophys. 1971, 146, 488-492. [CrossRef]

26. Lee, E.Y.C.; Whelan, W.J. Enzymatic Methods for the Microdetermination of Gl;ycogen and Amylopectin and their Unit-Chain Lengths. Arch. Biochem. Biophys. 1966, 116, 162-167. [CrossRef]

27. Wang, Z.; Okamoto, P.; Keutzer, J. A new assay for fast, reliable CRIM status determination in infantile-onset Pompe disease. Mol. Genet. Metab. 2014, 111, 92-100. [CrossRef] [PubMed]

28. Lowry, O.H.; Rosebrough, N.J.; Farr, A.L.; Randall, R.J. Protein measurement with the Folin phenol reagent. J. Biol. Chem. 1951, 193, 265-275. [CrossRef]

29. Calder, P.C.; Geddes, R. Rat skeletal muscle lysosomes contain glycogen. Int. J. Biochem. 1989, 21, 561-567. [CrossRef]

30. Murray, A.K.; Brown, B.I.; Brown, D.H. The molecular heterogeneity of purified human liver lysosomal $\alpha$-glucosidase [acid $\alpha$-glucosidase]. Arch. Biochem. Biophys. 1978, 185, 511-524. [CrossRef]

31. Huijing, F. A rapid enzymic method for glycogen estimation in very small tissue samples. Clin. Chim. Acta 1970, $30,567-572$. [CrossRef]

32. Dalrymple, R.H.; Hamm, R. A method for the extraction of glycogen and metabolites from a single muscle fiber. J. Food Int. J. Food Sci. 1973, 8, 439-444. [CrossRef]

33. Keppler, D.; Decker, K. Glycogen determination with amyloglucosidase. Methods Enzym. Anal. 1974, 3, $1127-1131$.

34. Roehrig, K.L.; Allred, J.B. Direct enzymatic procedure for the determination of liver glycogen. Anal. Biochem. 1974, 58, 414-421.

35. Bruss, M.L.; Black, A.L. Enzymatic microdetermination of glycogen. Anal. Biochem. 1978, 84, 309-312.

36. Murray, A.K. The Release of a Soluble Glycosylated Protein from Glycogen by Recombinant Lysosomal $\alpha$-Glucosidase (rhGAA) In Vitro and Its Presence in Serum In Vivo. Biomolecules 2020, 10, 1613. [CrossRef]

37. Dapson, R.W. Histochemistry of mucus in the skin of the frog, Rana pipiens. Anat. Rec. Adv. Integr. Anat. Evol. Biol. 1970, 166, 615-625. [CrossRef]

38. Leger, R.S.; Cooper, R.; Charnley, A. Cuticle-degrading enzymes of entomopathogenic fungi: Cuticle degradation in vitro by enzymes from entomopathogens. J. Invertebr. Pathol. 1986, 47, 167-177. [CrossRef]

39. Illingworth, B.; Larner, J.; Cori, G.T. Structure of glycogens and amylopectins: I. enzymatic determination of chain length. J. Biol. Chem. 1952, 631-640. [CrossRef]

40. Gunja-Smith, Z.; Marshall, J.J.; Mercier, C.; Smith, E.E.; Whelan, W.J. A revision of the Meyer-Bernfield model of glycogen and amylopectin. FEBS Lett. 1970, 12, 101-104. [CrossRef]

41. Goldsmith, E.; Sprang, R.; Fletterick, R. Structure of maltoheptaose by difference Fourier methods and a model for glycogen. J. Mol. Biol. 1982, 156, 411-427. [CrossRef]

42. Kirkman, B.E.; Whelan, W.J. Glucosamine is a normal component of liver glycogen. FEBS Lett. 1986, 194, 6-12. [CrossRef]

43. Rodén, L.; Ananth, S.; Campbell, P.; Manzella, S.; Meezan, E. Xylosyl Transfer to an Endogenous Renal Acceptor, Purification of the Transferase and The Acceptor and Their Identification As Glycogenin. J. Biol. Chem. 1994, 269, 11509-11513. [CrossRef]

44. Brown, B.I.; Brown, D.H. The Subcellular Distribution of Enzymes in Type II Glycogenosis and the Occurrence of an Oligo- $\alpha$-I,4Glucan Glucohydrolase In Tissues. Biochim. Biophys. Acta 1965, 110, 124-133. [CrossRef]

45. Brown, D.H.; Waindle, L.M.; Brown, B.I. The apparent activity in vivo of the lysosomal pathway of glycogen catabolism in cultured human skin fibroblasts from patients with type III glycogen storage disease. J. Biol. Chem. 1978, 253, 5005-5011. [CrossRef]

46. Raben, N.; Wong, A.; Ralston, E.; Myerowitz, R. Autophagy and Mitochondria in Pompe Disease: Nothing Is so New as What Has Long Been Forgotten. J. Med. Genet. 2012, 160, 13-21. [CrossRef]

47. Geddes, R.; Rapson, K.B. Post-mortem degradation of glycogen. FEBS Lett. 1973, 31, 324-326. [CrossRef]

48. Ugorski, M.; Seder, A.; Landlady, A.; Zopf, D. Studies on the metabolic origin of a glucose-containing tetrasaccharide in human urine. Br. J. Exp. Pathol. 1993, 1, 27-38.

49. Murray, A.K. $\beta$-Glucosidase/glucosyl transferase activity of isolated cell walls. Plant Physiol. 1971, 47, 42. 